\title{
Cathode Response Model and Literature Review of Metal Solubility in Carbonates
}

Topical Report

December 1994

Work Performed Under Contract No.: DE-AC21-90MC27394

For

U.S. Department of Energy

Office of Fossil Energy

Morgantown Energy Technology Center

Morgantown, West Virginia

\section{By}

M-C Power Corporation

Burr Ridge, Illinois

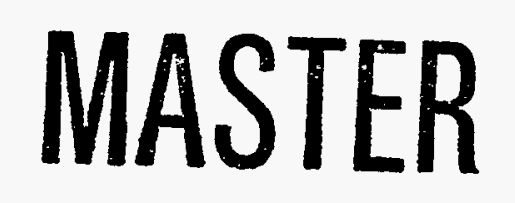

DIGTIEUTION DF THIS DOCUMENT IS UNLARTED WLC 


\section{DISCLAIMER}

This report was prepared as an account of work sponsored by an agency of the United States Government. Neither the United States Government nor any agency thereof, nor any of their employees, makes any warranty, express or implied, or assumes any legal liability or responsibility for the accuracy, completeness, or usefulness of any information, apparatus, product, or process disclosed, or represents that its use would not infringe privately owned rights. Reference herein to any specific commercial product, process, or service by trade name, trademark, manufacturer, or otherwise does not necessarily constitute or imply its endorsement, recommendation, or favoring by the United States Government or any agency thereof. The views and opinions of authors expressed herein do not necessarily state or reflect those of the United States Government or any agency thereof.

This report has been reproduced directly from the best available copy.

Available to DOE and DOE contractors from the Office of Scientific and Technical Information, 175 Oak Ridge Turnpike, Oak Ridge, TN 37831; prices available at (615) $576-8401$.

Available to the public from the National Technical Information Service, U.S. Department of Commerce, 5285 Port Royal Road, Springfield, VA 22161; phone orders accepted at (703) 487-4650. 


\title{
Cathode Response Model and Literature Review of Metal Solubility in Carbonates
}

\author{
Topical Report
}

Work Performed Under Contract No.: DE-AC21-90MC27394

For

U.S. Department of Energy

Office of Fossil Energy

Morgantown Energy Technology Center

P.O. Box 880

Morgantown, West Virginia 26507-0880

By

M-C Power Corporation

8100 S. Madison Street

Burr Ridge, Illinois 60521 


\section{SUMMARY}

The research described in this report is intended to explain some of the aspects of molten carbonate fuel cell system. The research currently being investigated is an important part of MCFC performance development. In this sense, the following four areas are investigated: *

\section{Task 1. Investigation of Wetting Angle Phenomena Related to MCFC Performance.}

This task is focused on clarifying the phenomena occurring in the boundary region of electrode, gas and molten carbonate under cathode operating conditions. Furthermore, the basic electrochemical performance of an in-situ lithiated $\mathrm{NiO}$ electrode is compared with that of an inert (gold) electrode. From these results, it is possible to infer the reaction mechanism of this electrode system.

\section{Task 2. Cell Performance Model:}

In this task, it is proposed to systematically compare experimental data, available in the literature or obtained from MCFC developers, with predictions from porous electrode models developed previously at IIT. To make this comparison possible, the filmed agglomerate model developed at IIT will be extended with the capability to control the degree of filling. For the MCFC cathode, the thin film model as well as the agglomerate model are compared.Finally, the effect of electrolyte filling on both the anode side and the cathode side is being investigated. Cathode and anode are porous gas-diffusion electrodes of different structure. The film agglomerate model of Yuh and Selman has been adapted to simulate both cathode and anode performance.A modified fixed-radius agglomerate model is used to account for the electrolyte filling effect.

\section{Task 3. Cathode Response Model.}

Under this task a large number of stationary and dynamic measurements have been made, by means of a 3-cm² lab-scale MCFC. Performance at very low $\mathrm{CO}_{2}$ partial pressures is compared with that of standard oxidant composition. The results confirm incomplete data obtained earlier on the laboratory and the bench scale MCFCs using low- $\mathrm{CO}_{2}$ oxidant which is necessary to suppress cathode dissolution and to increase cell life-time. 


\section{Task 4. Metal Solubility in Carbonates.}

The objective of this task is to analyze dissolution and oxidation/lithiation behavior of metal species, which are used as electrode or stack hardware in MCFC. The stack components of MCFC are in a partially wetted environment in carbonate. Corrosion of electrode and cell hardware materials occurs due to the corrosive behavior of electrolyte and gas environment. whose acidity and basicity affects solubility of $\mathrm{MeO}$. Information of gas solubility and solubility of oxides in carbonate is important to understand the corrosion behavior of MCFC components.

The oxidation characteristics of iron, nickel and chromium, elements for stainless steels will give us initial information about their dissolution behavior. We first studied metal oxidation under different gas conditions. At the same time, we have started building up theory of particle movement in carbonate melt for the development of a shorting model.

Degree of solubility can be resulted from $\mathrm{MeO}$ and carbonate interaction under corrosive gas environment with mixed potential process. Studies of metal dissolution that we see in the literature are mostly based on analytical methods. In order to account for electrochemical characteristic of metal ions in the melt, we have pursued ourselves to determine solubility in terms of electroanalytical methods. Since nickel is the basic components of both cathode and current collector, we focused our research on that metal.

Considering above perspective, explanation of nickel oxidation and shorting characteristics will be described. Three stages of nickel oxidation/lithiation having different characteristics are explained. Additionally, the cathodic dissolution and the particle behavior are discussed to understand and quantify the conditions that may lead to high ohmic shorting of MCFC. Finally, after explaining impact of dissolution on cell life, description of electroanalytical methods that have been used in our laboratory to determine solubility of metals in carbonate is outlined. 


\title{
INVESTIGATION OF WETTING ANGLE PHENOMENA
}

\author{
AND \\ TECHNOLOGY BASE STUDIES RELATED TO MCFC PERFORMANCE
}

\author{
DRAFT FINAL REPORT
}

\section{TASK 1. INVESTIGATION OF WETTING ANGLE PHENOMENA RELATED TO MCFC PERFORMANCE}

\subsection{Introduction}

This task is focused on clarifying the phenomena occurring in the boundary region of electrode, gas and molten carbonate under cathode operating conditions. This research consists of two studies. One of these is the formation of a meniscus at a gold electrode partially immersed in molten carbonate, in order to determine the reaction zone. Another is the obseivation of surface changes on a nickel electrode during in-situ oxidation and lithiation, in order to clarify electrolyte behavior during those processes. Furthermore, the basic electrochemical performance of an insitu lithiated NiO electrode is compared with that of an inert (gold) electrode.

\subsection{Measurements at an Inert Electrode}

Wetting has been studied at a gold foil electrode, under various oxidant atmosphere conditions, and at a nickel electrode, under standard oxidant atmosphere. The investigation makes use of the apparatus previously used by Matsumura and Selman [Ref. 1], with minor modifications. This system has four main parts (Fig. 1.1a). They are: an electric furnace containing a test cell; electrochemical measurement equipment; optical observation equipment; 


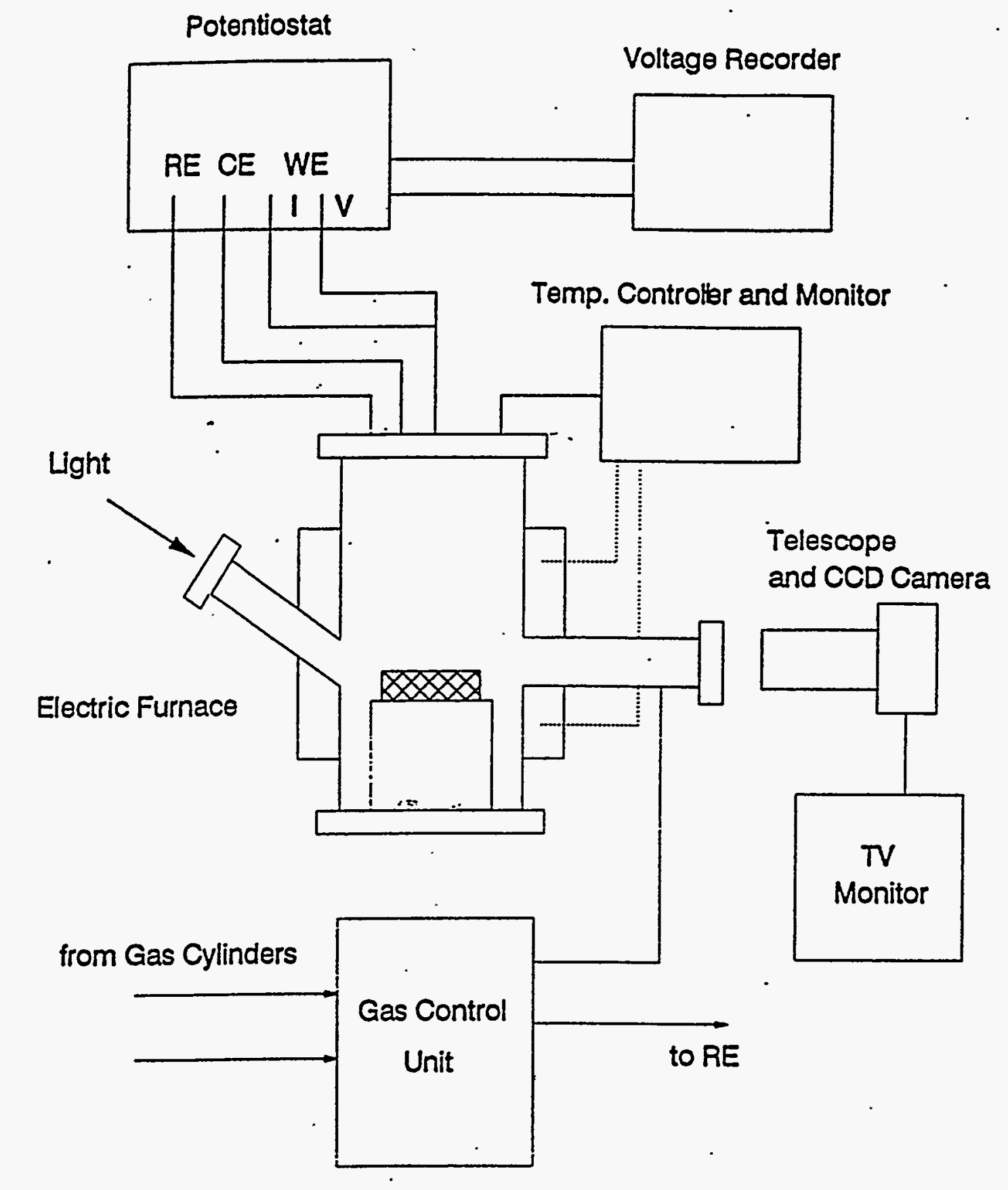

Fig 1-1 Apparatus used for wetting-angle measurements:(a) Controlled atmosphere chamber with optical and electrochemical equipment 


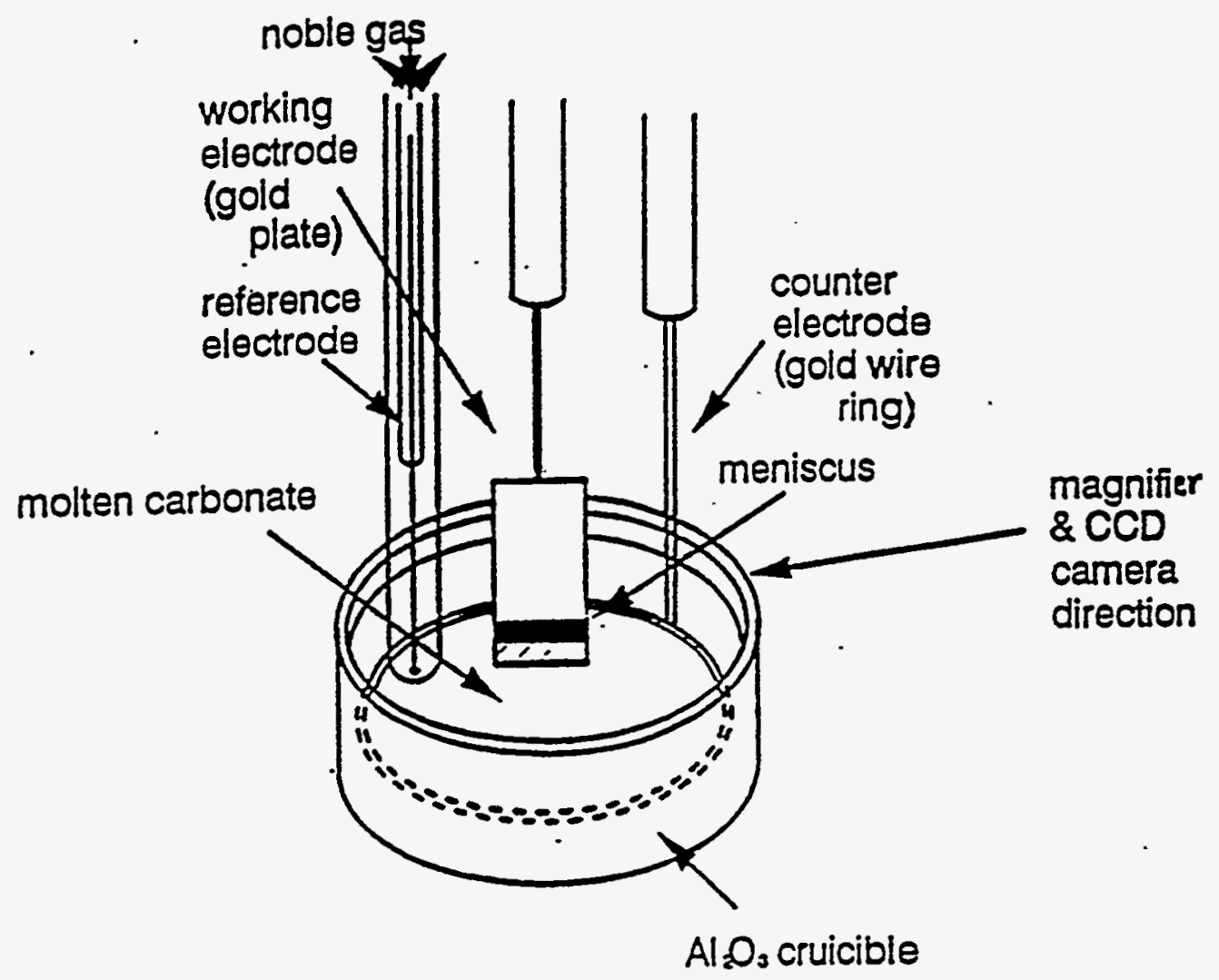

Fig. 1-1 Apparatus used for wetting-angle measurements:(b) Detail of cell and electrode configuration showing semi-immersed foil 
and a gas supply unit. The test cell and electrodes (Fig. 1.1b) are located in the middle of the furnace. The electrodes and electrolyte are specified as follows:

- Working electrode (WE) : : Gold foil of $25 \times 25 \times 0.1 \mathrm{~mm}$ with gold wire of $\phi 1 \mathrm{~mm}$ : Nickel foil of $25 \times 25 \times 0.25 \mathrm{~mm}$ with gold wire of $\phi 1 \mathrm{~mm}$

- Reference electrode (RE) : Partially coiled gold wire of $\phi 0.5 \mathrm{~mm}$

- Counter electrode (CE) : Ringed gold wire of $\phi 1 \mathrm{~mm}$

- Electrolyte

: Eutectic carbonate $\left(\mathrm{Li}_{2} \mathrm{CO}_{3} / \mathrm{K}_{2} \mathrm{CO}_{3}=62 / 38\right.$ mole \%)

\subsection{Effect of Polarization on Wetting Properties}

1.3.1. Depth of Electrode: The current through the WE with cathodic potential applied between RE and WE was measured at different immersed depths of the WE. Under constant temperature $\left(650^{\circ} \mathrm{C}\right)$, constant gas conditions $\left(\mathrm{O}_{2} / \mathrm{CO}_{2} / \mathrm{N}_{2}=15 / 30 / 55 \mathrm{~mol} \%\right)$ and constant applied potential between $\mathrm{RE}$ and WE (WE-RE $=-200 \mathrm{mV}$ ), the current through the WE was monitored while its depth of immersion was changed form $10 \mathrm{~mm}$ to $15 \mathrm{~mm}$ and from $15 \mathrm{~mm}$ to $10 \mathrm{~mm}$. The current change is shown schematically in Figs. 1.2(a) and (b). While the immersion was changing from $10 \mathrm{~mm}$ to $15 \mathrm{~mm}$, the current showed a temporary increase. When changing the immersion from $15 \mathrm{~mm}$ to $10 \mathrm{~mm}$, the current showed first a temporary decrease, then relaxed to almost the same value as before immersion. Fig. 1.3 shows the influence of the immersed depth on the current. It seems that the current depends on the immersion depth but the influence becomes less with increased immersion. At more than $10 \mathrm{~mm}$ immersion, the characteristics are independent of immersion. This suggests that electrochemical reaction takes place mainly near the electrolyte surface.

The transient phenomena may be explained as follows. In case (a), where immersion was changed from 10 to $15 \mathrm{~mm}$, the electrolyte forming the meniscus, which may be expected to include more dissolved oxygen and carbon dioxide gas, is dragged into the melt. The dissolved species immediately react at the immersed electrode surface, which causes an increase of current, which relaxes to zero. On the other hand, in case (b), where the electrode was brought back to its original position, it seems that the electrolyte forming the meniscus is stretched upward somewhat due to the interaction forces between electrode surface and electrolyte. Therefore, the 


\section{gold electrode}

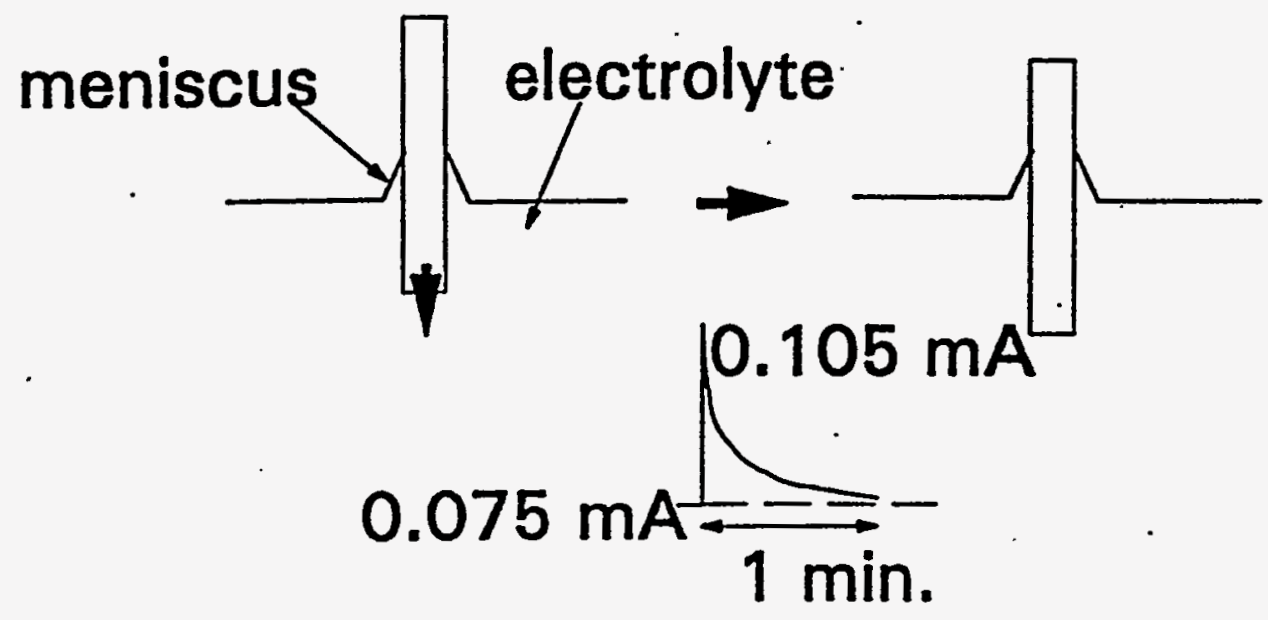

(a) Electrode moving down

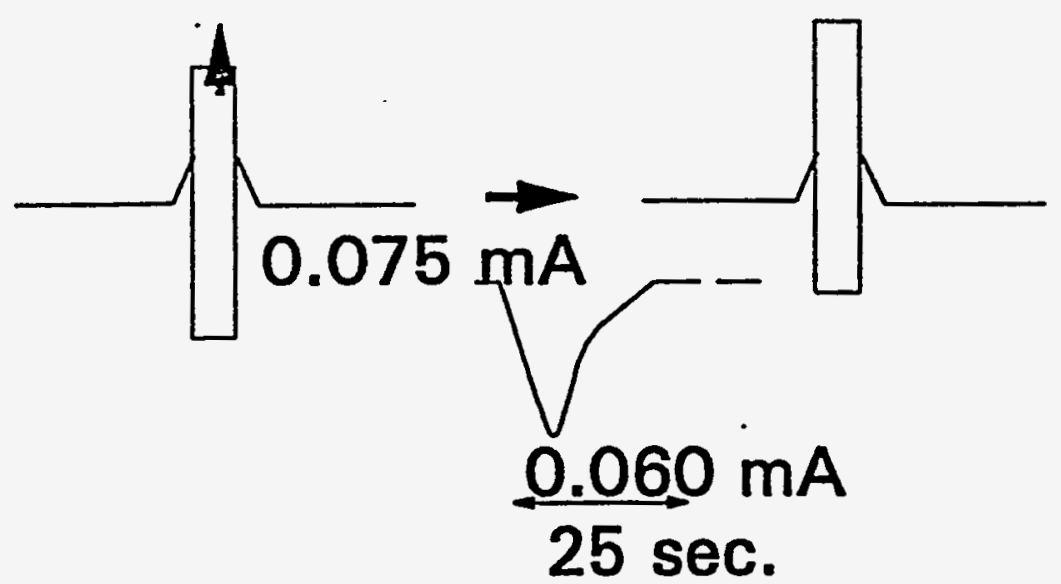

(b) Electrode moving up

Fig. 1-2 Schematic of current response with change in immersed depth 


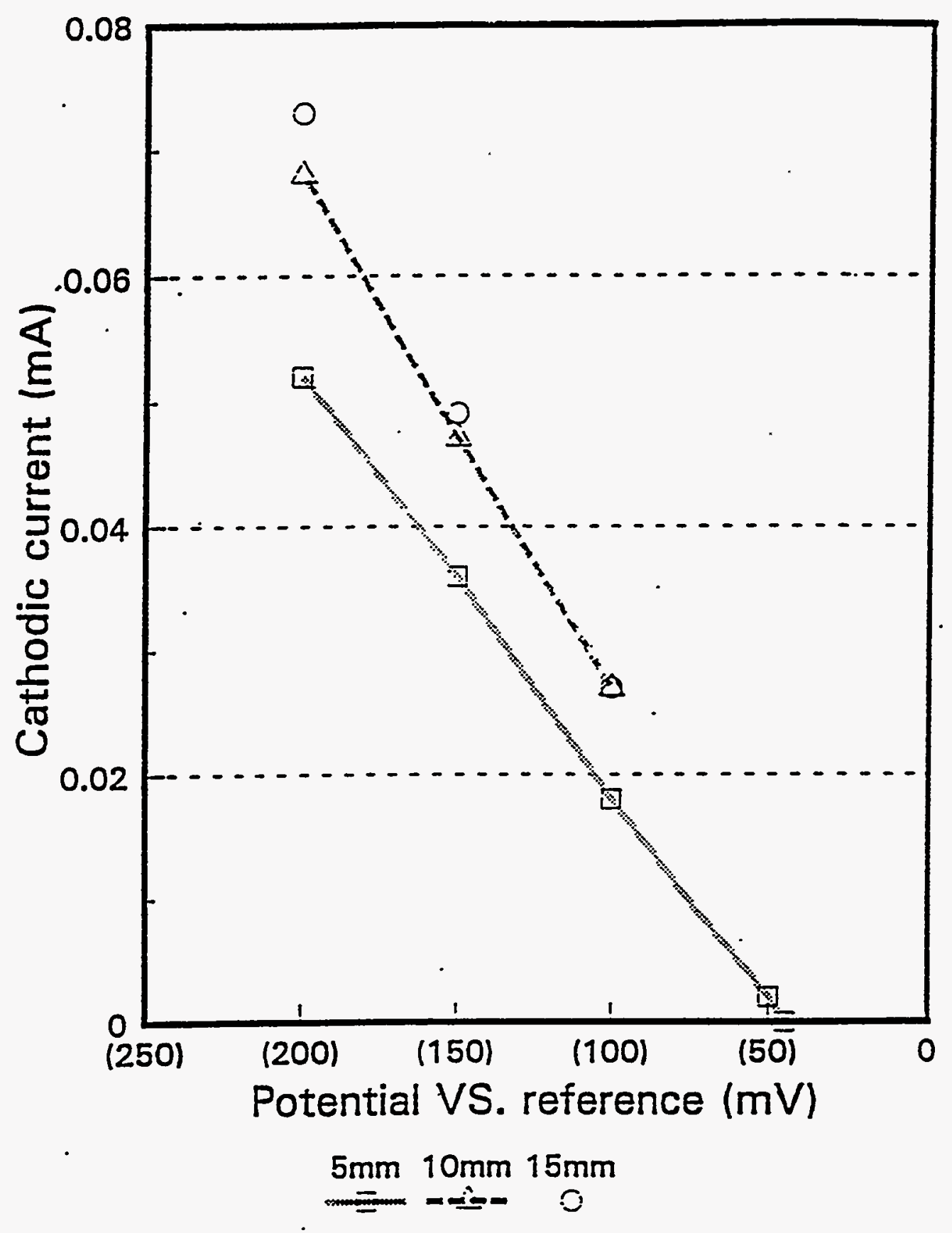

Effect of immersed depth

(Temperature: 610)

Fig.1.3.Effect of electrode immersion on current-potential behavior 


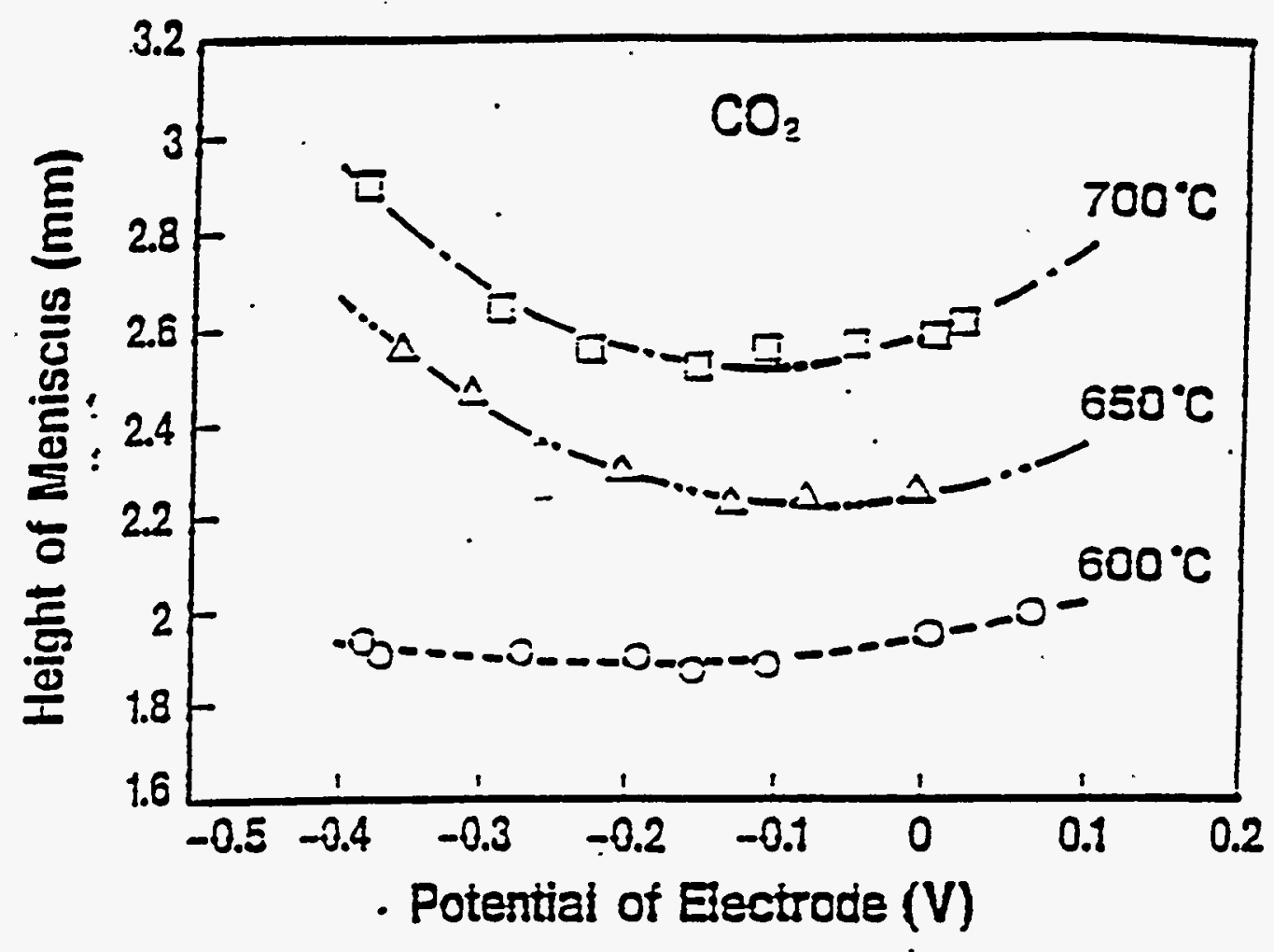

Fig.1.4.Meniscus height measurements at a gold foil electrode semi-immersed in Li-K carbonate at three temperatures. The effect of polarization is shown.(Wetting angle is calculated from the meniscus height, and its behavior with polarization is approximately inverse of that of meniscus height.) 
ionic resistance between the reaction site and the bulk melt increases temporarily, and hence the current is decreases temporarily.

1.3.2. Temperature Effect: In continued measurements, the current through the WE at $10 \mathrm{~mm}$ immersion under applied cathodic potential was measured for different temperature conditions. The current depends on temperature and increases with temperature at constant applied potential. This increase in current is caused by a decrease of reaction overpotential and/or electrolyte resistance with temperature. However, over a range of temperatures, it has been found that the adsorbed ions may, with equal likelihood, be cathodically active species such as peroxide and superoxide. The behavior of working electrode at three different temperatures is shown in Fig. 1.4. The quasi-parabolic response at $600^{\circ} \mathrm{C}$ is relatively shallow, and the data near the electrocapillary minimum appear to be remarkably similar to those for low-oxygen, high $\mathrm{CO}_{2}$ oxidant compositions, which are in equilibrium with melts that are rich in $\mathrm{O}^{2-}$ and to a lesser extent in $\mathrm{O}_{2}^{2-}$.

1.3.3. Effect of Gas Composition: The current through the WE at $10 \mathrm{~mm}$ immersion under applied cathodic potential was measured for different gas conditions at $650^{\circ} \mathrm{C}$. Fig. 1.5 shows the voltage vs. current characteristics for each gas condition. These two characteristics show similar behavior under different gas compositions. The results agree with previous work. This means that the gas solubility and its transport to the reaction site does not play a role in the electrochemical reaction occurring on the electrode surface.

1.3.4. Conclusion: From these results, it is possible to infer the reaction mechanism of this electrode system as follows. Electrochemical reactions on the immersed part of the electrode are controlled by the concentration of the reactant species $\left(\mathrm{O}^{2-}\right.$ or $\left.\mathrm{CO}_{2}\right)$ near the surface. Electrochemical reactions on the non-immersed part of the electrode are controlled by the mobility of the reaction product $\left(\mathrm{CO}_{3}^{2}\right)$.

There is no evidence for the formation of a thin electrolyte film above the meniscus at a gold electrode and for its contribution to the electrochemical reaction. If there would be such a thin film it must contribute to the electrochemical reactions, therefore current change should be in the opposite direction to the previously defined case. 


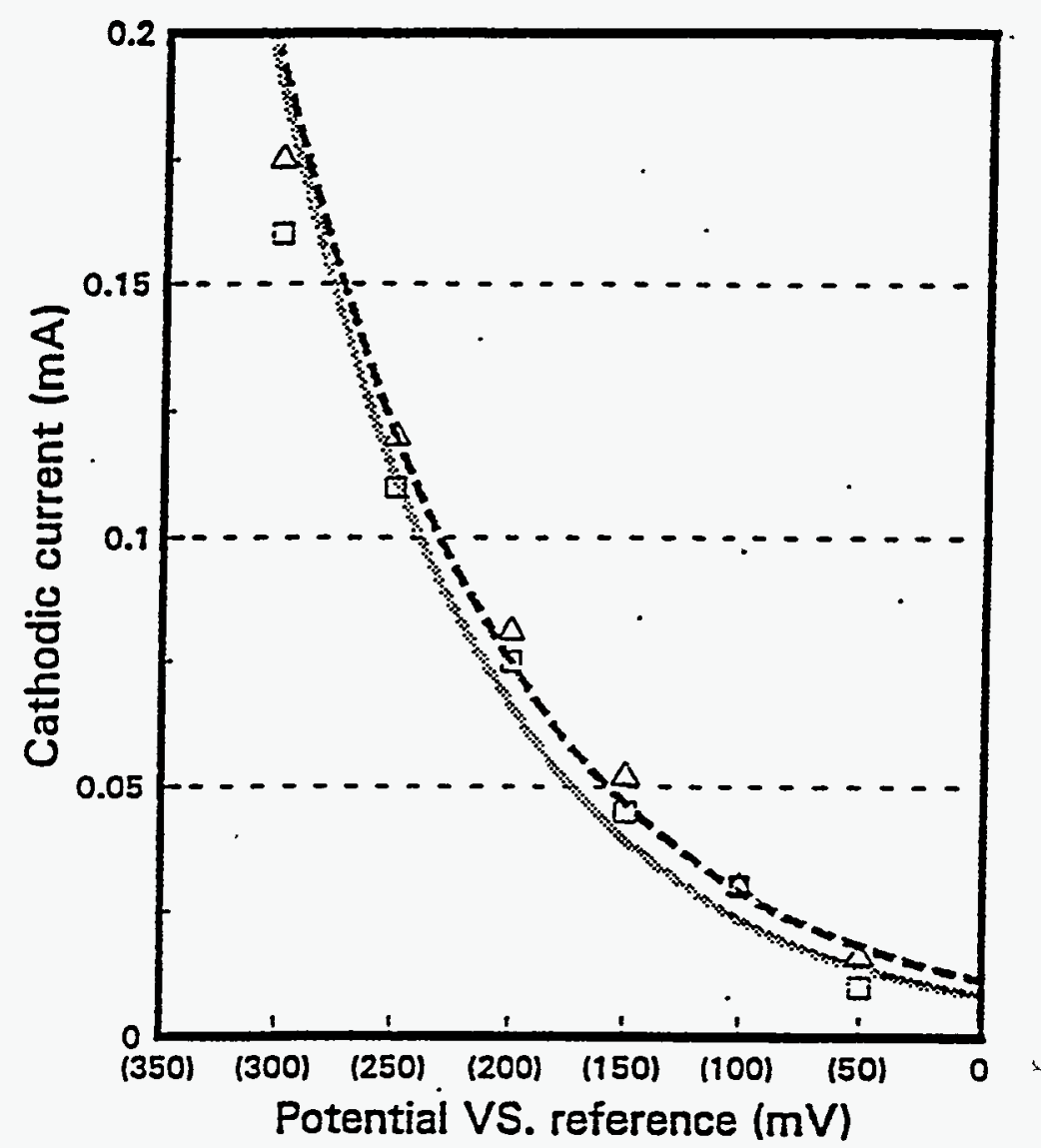

Air/CO2 02/CO2

$70 / 30 \quad 33 / 67$

-

Effect of gas composition

(Immersed depth of electrode : $10 \mathrm{~mm}$ )

Fig.1.5Effect of gas composition on current-potential behavior 
It was also possible to determine the cross section of the meniscus by means of back lighting. Although the geometrical scale of the shape could not be measured because it was not clear, it was confirmed that the contact angle of electrolyte to gold electrode is almost 60 degrees. Therefore, a clear boundary line between electrode and electrolyte could be observed, however, a thin film above the meniscus could not be observed. This means that a smooth gold electrode is not well wetted by molten carbonate even under cathode gas conditions.

At an inert (gold) electrode surface tension, as determined from the height of the meniscus at a partially submerged gold electrode, goes through a maximum when the applied potential is varied from cathodic to anodic with respect to the standard oxidant reference electrode. In the absence of oxygen, the minimum is very shallow and displaced in the positive direction by as much as $100 \mathrm{mV}$. The parabolic response to potential can be analyzed in part on the basis of principles which are well-known from aqueous solution thermodynamics ("electrocapillary effect" and Lippmann-Helmholtz equation). The analysis leads to the conclusion that some oxygen ions present in the meit are specifically (i.e., chemically) adsorbed on the metal surface. In our earlier publication on these measurements, the adsorbed ions were tentatively identified as oxide ions. [Ref. 1] This would be consistent with the slow kinetics of oxide neutralization:

$$
\mathrm{O}^{2-}+\mathrm{CO}_{2} \rightarrow \mathrm{CO}_{3}^{2-}
$$

\subsection{Measurement at a Nickel Electrode}

In continued experiments on wetting phenomena a nickel electrode was studied in a $\mathrm{CO}_{2}$ atmosphere. The meniscus on the nickel electrode could be observed clearly. The contact angle between electrode and electrolyte was approximately 50 degrees. The behavior of the electrode was next observed when $\mathrm{CO}_{2}$ atmosphere was changes to include oxygen.

1.4.1. Open Circuit Potential of Nickel Electrode in $\mathrm{CO}_{2}$ : The open-circuit potential and the surface of the nickel electrode observed continuously after partial immersion in the melt, under no load condition. The appearance of the foil is observed optically and recorded on videotape. 
The potential between the nickel electrode and the reference electrode was $-640 \mathrm{mV}$ in the beginning. The potential increased with time and finally reached $-750 \mathrm{mV}$. This value agrees with the equilibrium potential of nickel. oxidation. A sharp meniscus was observed at the electrode under these conditions, and the potential of the electrode remained steady at this value. Hence, it seems that a nickel electrode is stable in a pure $\mathrm{CO}_{2}$ atmosphere, just as it is without electrolyte. In addition, the contact angle measured appears not to be so different from that at a gold electrode in $\mathrm{CO}_{2}$ atmosphere.

\subsubsection{Open Circuit Potential during Oxidation and Lithiation: Fig. 1.6 shows a characteristic} potential-time plot, which corresponds fairly well with the results of some detailed experiments discussed below (Task 4). Minor variations are possible, such as the occurrence or absence of the first, short plateau, and the length of the main plateau at $-250 \mathrm{mV}$. These variations depend on the oxidant gas composition and on the extent of immersion of the foil.

When a gas mixture containing oxygen was supplied, the potential initially decreases similar to previous experiments. In this initial stage, it was observed that the surface of the nonimmersed part of the electrode becomes cloudy as the potential drops. Next, bubbles rise from inside the electrolyte and some vapor is released from the surface of the electrolyte into the gas phase. Some of the vapor seems to be adsorbed on the electrode surface. These phenomena were observed about 1 hour after the mixed gas supply started. Following this, some reactions were observed on the non-immersed part of the electrode. The electrode surface appeared to be covered with electrolyte and some reaction was occurring with gas generation. In this stage, the potential was decreasing gradually toward a plateau at about $-470 \mathrm{mV}$, which was reached after about 4 hours. The plateau lasted for about 17 hours, while the surface reactions continued.

After the first plateau, the potential dropped suddenly by about $100 \mathrm{mV}$ and began to decrease again gradually. In this stage, some cracks and cleavages were seen on the top part of the electrode. After 50 hours from the start of the experiment, the potential reached -220 to -230 $\mathrm{mV}$, and a second plateau appeared. During this stage, many corrosion products were observed in the electrolyte bath. These tended to move toward the surface of the ceramics immersed in the bath. At the end of this stage, the reaction seems to taking place on the non-immersed electrode surface had stopped. However, instead of this reaction, gas bubbles had started rising from the 


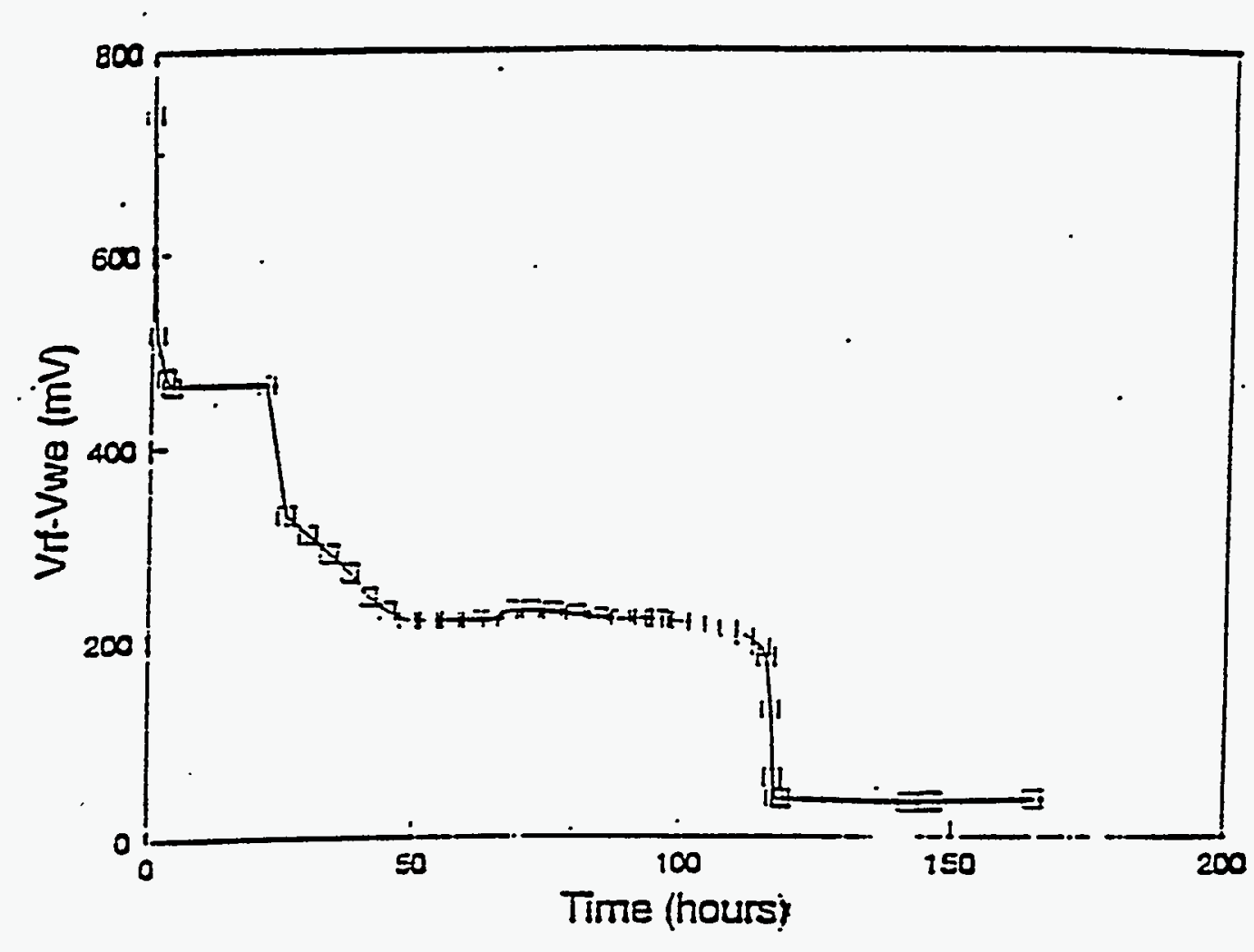

Fig.1.6.Potential-time behavior of nickel partially immersed in $\mathrm{Li}-\mathrm{K}$ carbonate under standard oxidant gas, at open circuit. 
inside of the electrolyte bath. After about 120 hours, the potential again began to decrease and reached $-40 \mathrm{mV}$ in only 1 hour. Gas development from the electrode surface of the immersed part had stopped by this time. After the potential had reached about $-44 \mathrm{mV}$, it did not change any more.

After the electrolyte became solid, it was tried to remove the electrode from the electrolyte. But parts of the electrode broke during this process. Especially, the non-immersed part of the electrode is fragile. On the other hand, the part of the electrode that was completely immersed in the melt could be easily removed in the original shape. A cross section of this part of the electrode had five layers. The innermost layer looked like Ni metal. The second and third layers on either side of the metal had of green and black color, respectively. The surface of the green colored layer was smoother than that of the black colored layer.

1.4.3. Stages of Potential Decay: Overall, the optical record of the oxidation of the nickel foil shows distinct stages, which correspond to those of the potential-time curve. In the initial stage the non-immersed part of the foil is becoming completely covered by electrolyte, and surface oxidation presumably is occurring uniformly, but without visible gas evolution. This stage corresponds to the steep initial drop in potential and, in some cases, stabilization of the potential on a plateau at $-450 \mathrm{mV}$, during the first 20 hours. Next, the color of the immersed part of the foil changed completely (from dark to light) and appears to become covered with pits where intense gas evolution as well as oxidation takes place. This stage lasts very long (100-200 hours) and corresponds to the main plateau at $-200 \mathrm{mV}$. Finally, the oxidation of the foil is complete and the visible gas evolution subsides. This is accompanied by a final drop in potential, to the (oxygen, $\mathrm{CO}_{2} /$ carbonate) equilibrium potential of approximately $-40 \mathrm{mV}$. The potential changes have plateaus similar to those recorded for completely immersed electrodes as reported earlier.

Moreover, in the initial stage of this experiment, some electrolyte moving along the electrode surface was observed on the non-immersed part of the electrode. It seems that the nonimmersed part of the electrode is covered with electrolyte initially, and that some reaction, i.e., oxidation or corrosion, and lithiation, starts occurring. "Hot corrosion" reactions may take place on the non-immersed part because the conditions for hot corrosion may be satisfied. On the other hand, it seems that the oxidation reaction on the part of the electrode that is completely 
immersed in the melt, is relatively slow due to poor supply of oxygen. Ni metal was observed even after 120 hours, which is one piece of evidence for this conclusion.

1.4.4. Conclusions: There are several remarkable and unexpected aspects to these optical observations. First, intense gas evolution is found to occur during stage II (main plateau). An explanation for these and other features has been developed in Task 4; below. Second, during stage I (and presumably later as well) fine particles are seen to spall from the foil and to be convected away from it, down the meniscus. It is not clear if these particles are of nickel metal or nickel oxide, but in any case the oxidation process apparently creates intense local stresses at the oxidation front. The third surprising observation is that this particle motion takes place at relatively high apparent speed (estimated at several $\mathrm{mm} / \mathrm{s}$ ). This indicates that the electrolyte undergoes intense convection during the oxidation process. Such convection may be caused by heat effects or by surface energy gradients (Marangoni effect, interfacial turbulence), or both.

These observations are very relevant for an understanding of the in-situ oxidation process to which nickel is usually subjected in MCFC stacks. In particular the role of heat effects (which are known to be considerable during in-situ nickel oxidation) and the exact extent of electrolyte loss associated with the oxidation process, is of interest. Experiments in which nickel is exposed to low-level oxidant atmospheres and reducing atmospheres are now under way. Work is in progress to determine how the observed phenomena depend on gas composition. Dynamic current measurement (AC Impedance) may be useful to discuss the limiting factors of the electrochemical reactions on meniscus. It should be helpful for determining the extend of the actual reaction site under operation conditions.

\subsection{Conclusions of Wetting and Oxidation Studies}

1. The contact angle on an inert (gold) electrode was almost 60 degrees, determined by observation of the meniscus height. There appears to be no thin film formation above the meniscus.

2. Electrolyte movement from the meniscus to the non-immersed part of the nickel electrode was observed in the initial stage, followed by a hot corrosion reaction at this part of the 
electrode. The hot corrosion reaction is possible because the nickel electrode is wettable under cathode conditions in the MCFC. Although the reactions take place, involve gas, solid and liquid phases, the detailed mechanism could not be clarified in this experiment.

3. A cross section of the immersed part of the Ni electrode after steady-state has been reached seems to have five layers. The central layer seems to be Ni metal. The middle and outer layers are green and black, respectively. The surface of the green colored layer seems more smooth than the black colored layer.

4. The polarization characteristic of the in-situ lithiated NiO electrode shows an almost linear. relationship between the current and the applied potential. The influence of the depth of immersion on these characteristics are recognizable at high applied potential. Under applied potential the current shows the tendency to increase with immersion. However, under an applied potential of less than $300 \mathrm{mV}$, depth of immersion makes no difference.

\section{TASK 2. CELL PERFORMANCE MODEL}

\subsection{Introduction}

In this task it is proposed to systematically compare experimental data, available in the literature or obtained from MCFC developers, with predictions from porous electrode models developed previously at IIT [Ref. 2]. To make this comparison possible, the filmed agglomerate model developed at IIT will be extended with the capability to control the degree of filling (i.e., fraction of the void volume occupied by the electrolyte). For the MCFC cathode, the thin film model as well as the agglomerate model would be employed.

The film-agglomerate model has been used previously to study how the MCFC cathode electrode perfoemance is affected if one employs a cathode material with different electrocatalytic properties and electronic conductivity, electrode thickness, electrostructure, active surface and variable electrolyte filling. Cathode and anode of the MCFC are porous gas- 
diffusion electrodes. Therefore, the film agglomerate model can be adapted to simulate both cathode and anode performance.The influence of electrolyte filling was found to depend strongly on the relative magnitude of voltage loss components;i.e., on the ratios of ohmic resistance, mass transfer resistance,and kinetic activation resistance.The optimal value of electrolyte filling,i.e., the value for which polarization is minimal, is associated with a switch of dominant voltage loss from ohmic resistance control or mass transfer control to kinetic activation control [Ref.2]. For the cathode, one would recommend a high level of electrolyte filling when the electrode is thick or has poor electronic conductance; and a very low level of electrolyte filling when the electrode is thin or has a low intrinsic exchange current density. These recommendation are based on the modified fixed-radius agglomerate model. Since the MCFC anode is acting as an electrolyte reservoir during long-term fuel cell operation, i.e., the amount of carbonate in the anode is continuously reduced carbonate, the effect of electrolyte filling on the anode is critical for long-term cell performance.

\subsection{Thin Film Model and Agglomerate Model}

In the thin film model the porous structure is described as consisting of cylindrical pores. The gaseous reactants in the macropores dissolve in a thin electrolyte film covering the pore wall, diffuse across the film and react electrochemically on the pore wall.

In the agglomerate model, the electrode structure is regarded as consisting of cylindrical agglomerates of electrocatalyst particles. The model used by Yuh and Selman [Ref.3] also includes a film of the electrolyte on the exterior surface of the agglomerate. In this case the. reactants diffuse through the film to react on the exterior surface of the agglomerate as well as on the interior surface of the micropores. On the other hand, Kunz et al. [Ref.4] assume that the electrochemical reaction occurs only on the interior surface. In this model, the degree of filling of the pores is taken into account by calculating an agglomerate diameter from porosimetry data. The agglomerate porosity increases at the same time that the amount of electrolyte increases. Predicted performance as a function of electrolyte content for cathodes with different pore size distributions was found to be in good agreement with experimental results, by Kunz et al. 
The relative importance of interior and exterior agglomerate surface in these two models must be compared and the agreement with experimental results checked to determine which one of the two approaches is the more realistic one. In Table 2.1 the input data and structural parameters used are given.

It is clear from the values of the fitted parameters in Table 2.1 that using only the inner surface area in the model one needs an unreasonably high value of the effective diffusion coefficient of oxygen. At higher current densities, the polarization curve for this case will become even more non linear due to increasing mass transfer limitations in the micropores. Since the experimental polarization curves have a quasi-linear character, it may be anticipated that a good fit to experimental data is generally easier to obtain with an agglomerate model that takes into account the reaction on the exterior surface of the agglomerate.

Table 2.1. Values of input data and structural parameters used for agglomerate modeling (assuming cylindrical agglomerates)

Neglecting outer surface

$\begin{array}{lll}\mathrm{D}_{\text {oxygen }}\left(\mathrm{m}^{2} \mathrm{~s}^{-1}\right) & 6.8 \times 10^{-10} & 3.2 \times 10^{-7} \\ \mathrm{D}_{\mathrm{CO2}}\left(\mathrm{m}^{2} \mathrm{~s}^{-1}\right) & 5 \times 10^{-10} & 9.6 \times 10^{-10} \\ \mathrm{i}_{0} \quad\left(\mathrm{~A} \mathrm{~m}^{-2}\right) & 48 & 25 \\ \mathrm{~K} \quad\left(\mathrm{~mol} \mathrm{~m}^{-3} \mathrm{~atm}^{-0.25)}\right. & 0.05 & 0.05 \\ \mathrm{r} \quad(\mathrm{mm}) & 3.5 & 3.5 \\ \varepsilon_{\mathrm{M}} & 0.57 & 0.57 \\ \varepsilon_{\mathrm{m}} & 0.19 & 0.19 \\ \text { Fraction active surface } & 0.34 & 0.34\end{array}$




\subsection{The influence of electrolyte film thickness}

A realistic model for the MCFC should not only predict polarization curves in good agreement with measurements, but also predict reasonably well the influence of the degree of electrolyte filling on the electrochemical performance. The homogeneous agglomerate model of Kunz et al. [Ref. 4] takes this parameter into account by relating it to the radius of the agglomerate, while the model of Yuh and Selman [Ref. 3] does not describe this effect. For a cylindrical agglomerate, the following relation between electrolyte fill and film thickness may be derived from geometric considerations :

$$
\delta=R\left[\left(1-\varepsilon_{m}+\frac{\varepsilon_{f}}{\left(1-\varepsilon_{M}\right)}\right)^{1 / 2}-1\right]
$$

The major effect of the electrolyte film on the reaction rate is that it adds an external mass transfer resistance that increases with the film thickness. This effect may also be investigated separately by calculating the global limiting current density that would be obtained if the diffusion rate of superoxide or peroxide ions through the film were the controlling step. Fig. 2.1 shows this limiting current density as a function of the electrolyte film thickness. The results obtained suggest that once the electrolyte has covered the electrocatalyst particles and filled the micropores, the film thickness does not grow uniformly. Therefore, a uniformly growing electrolyte film model is not physically realistic. Adding electrolyte to an initially dry electrode would lead to the following stages: (1) spreading of a thin electrolyte film over the surface; (2) filling of the micropores with electrolyte; (3) growth of a non-uniformly thick external electrolyte layer on the agglomerates. The recently developed modified agglomerate models i.e., (a). the partially drowned agglomerate model; (b). the chain of spherical agglomerates model, considered these facts. The two modified agglomerate models are essentially based on the model of Kunz et al. [Ref. 4] but there are two important differences. The first difference is that the models take into account also the participation of the exterior surface area in the electrochemical reaction, The second is that the equation for calculating the agglomerate radius from porosimetry data is the physically more relevant relationship. 


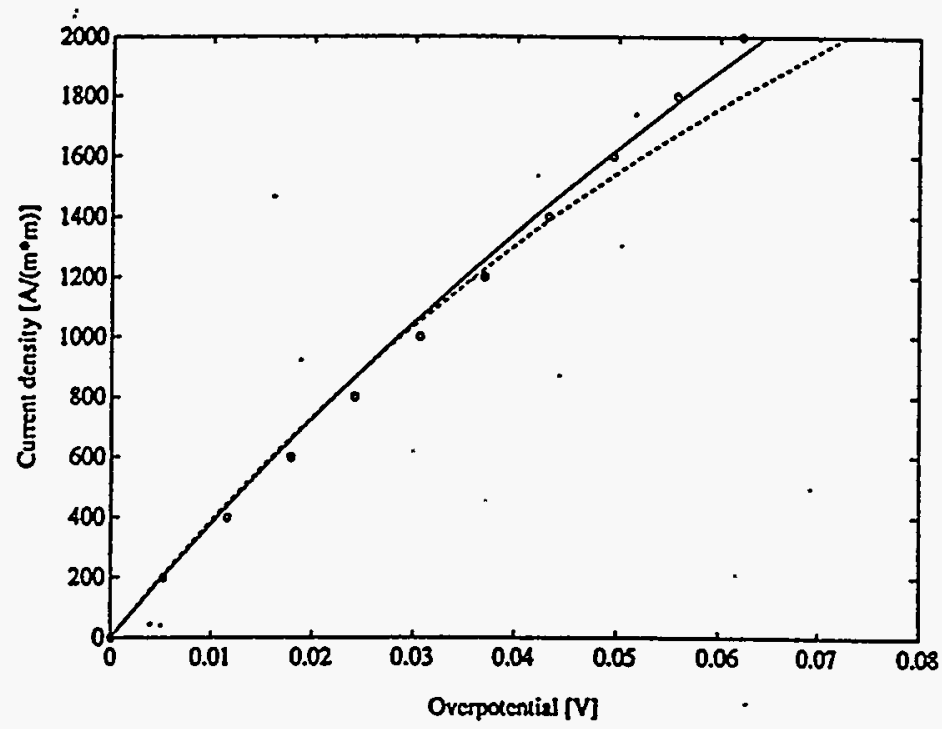

Fig 2-1.Polarization curves for a NiO cathode . Open simbols: experimental points; curve predicted by the agglomerate model taking into account both an exterior and interior surface area; dashed line:curve predicted by the agglomerate model taking into account only an interior surface area 


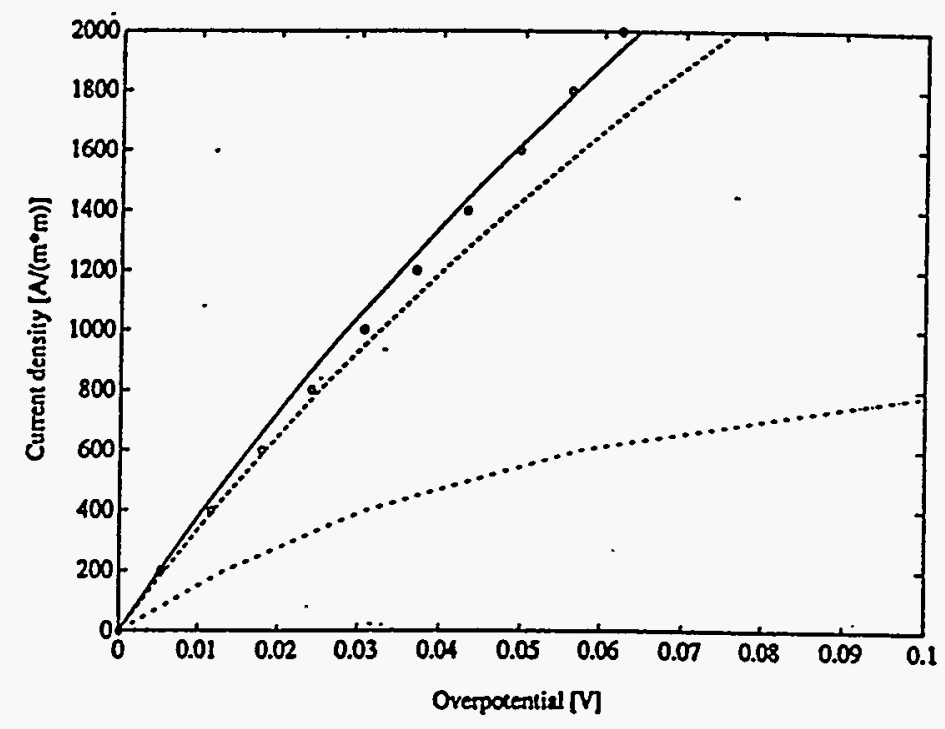

Fig 2-2.Polarization curves for a NiO cathode. Open simbols: experimental points; curve predicted by the agglomerate model taking into account only the exterior surface area;dot- dashed line:curve predicted by the agglomerate model taking into account only an interior surface area 


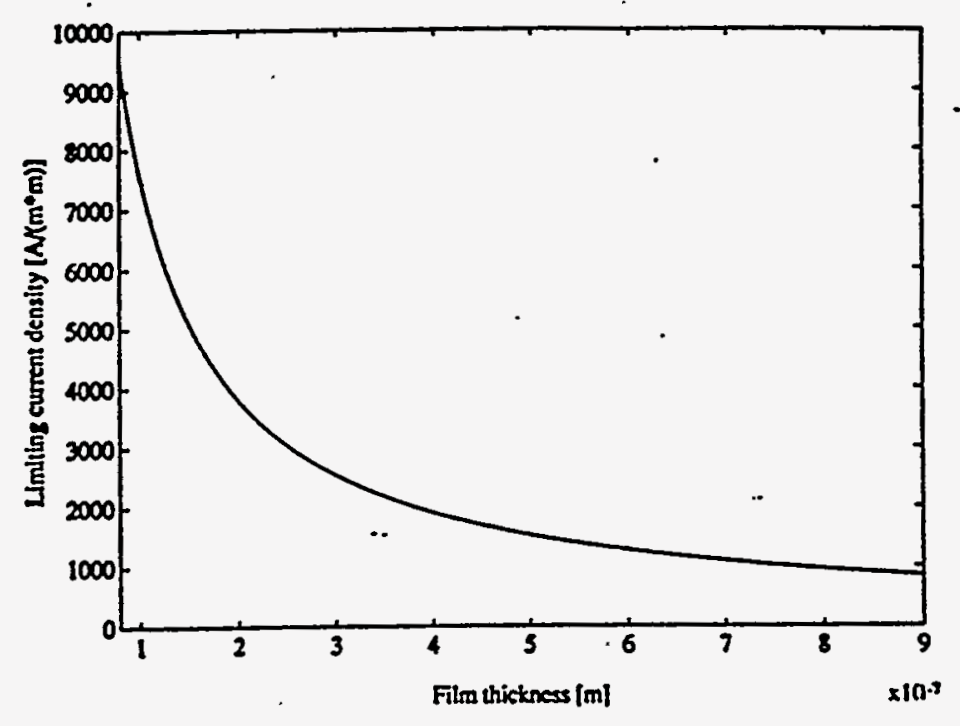

Fig 2-3. Global limiting current density as a function of electrolyte film thickness 


$$
R=\frac{V_{f}}{\varepsilon_{f} \frac{d V}{V_{s}}}
$$

Here $\varepsilon_{f}$ represents electrolyte fill. The effect on the overall electrochemical performance is shown in Fig. 2.2 and 2.3.

\subsection{Fixed-Radius Agglomerate Model:}

A modified fixed-radius agglomerate model is used to account for the electrolyte filling effect, and the sequence of electrolyte filling is illustrated in Fig.1. In the beginning, $\mathrm{V}_{e}<$ $\max \left\{V_{c, d r y}\right\}$, i.e., the electrolyte volume is smaller than the maximum electrolyte filling volume which would be required to fill exactly the agglomerate without forming around it. In that case, the outward-facing part of the agglomerate mass is not covered by a continuous film or - electrolyte, and the corresponding part of the agglomerate surface area is not active. In stage B, $\mathrm{V}_{\mathrm{c}}=\max \left\{\mathrm{V}_{\mathrm{e}, \mathrm{dry}}\right\}$, the electrolyte exactly fills the agglomerate, all the catalyst particles are active and no continuous film surrounds the agglomerate externally. In stage $\mathrm{C}, \max \left\{\mathrm{V}_{\mathrm{e}, \mathrm{dry}}\right\}<\mathrm{V}_{\mathrm{e}}<$ $\max \left\{\mathrm{V}_{\mathrm{e}, \text { film }}\right\}$, i.e., the elctrolyte volume is more than sufficient to fill the agglomerate and the excess elctrolyte forms an external film, but does not exceed the limit corresponding to maximum film thickness.In case $\mathrm{C}$, a continuous film forms around the agglomerates. If one keeps increasing the electrolyte filling until $\mathrm{V}_{\mathrm{e}}>\max \left\{\mathrm{V}_{\mathrm{e}, \mathrm{film}}\right\}$ i.e., stage $\mathrm{D}$, the elctrolyte can only be accommodated by filling the macropores starting from the tile side.

To develop this electrolyte filling structure model, one more parameter, the radius of the macropore $R_{m}$ is required. Its value may be estimated from SEM pictures or from the pore size distribution. A new parameter $\mathrm{q}_{\mathrm{e}}$ is defined, which is the volume fraction of electrolyte contained in film and agglomerate. It can be calculated from primary input data by

$$
q_{e}=\frac{1}{V_{c}}\left[\frac{\left(A_{p} L\right)(R+\delta)^{2}}{(R+\delta)^{2}+R_{m}^{2}}\right]-\frac{V_{c}}{V_{e}} \ldots . .(1)
$$

The height to which the macropore is filled with electrolyte is 


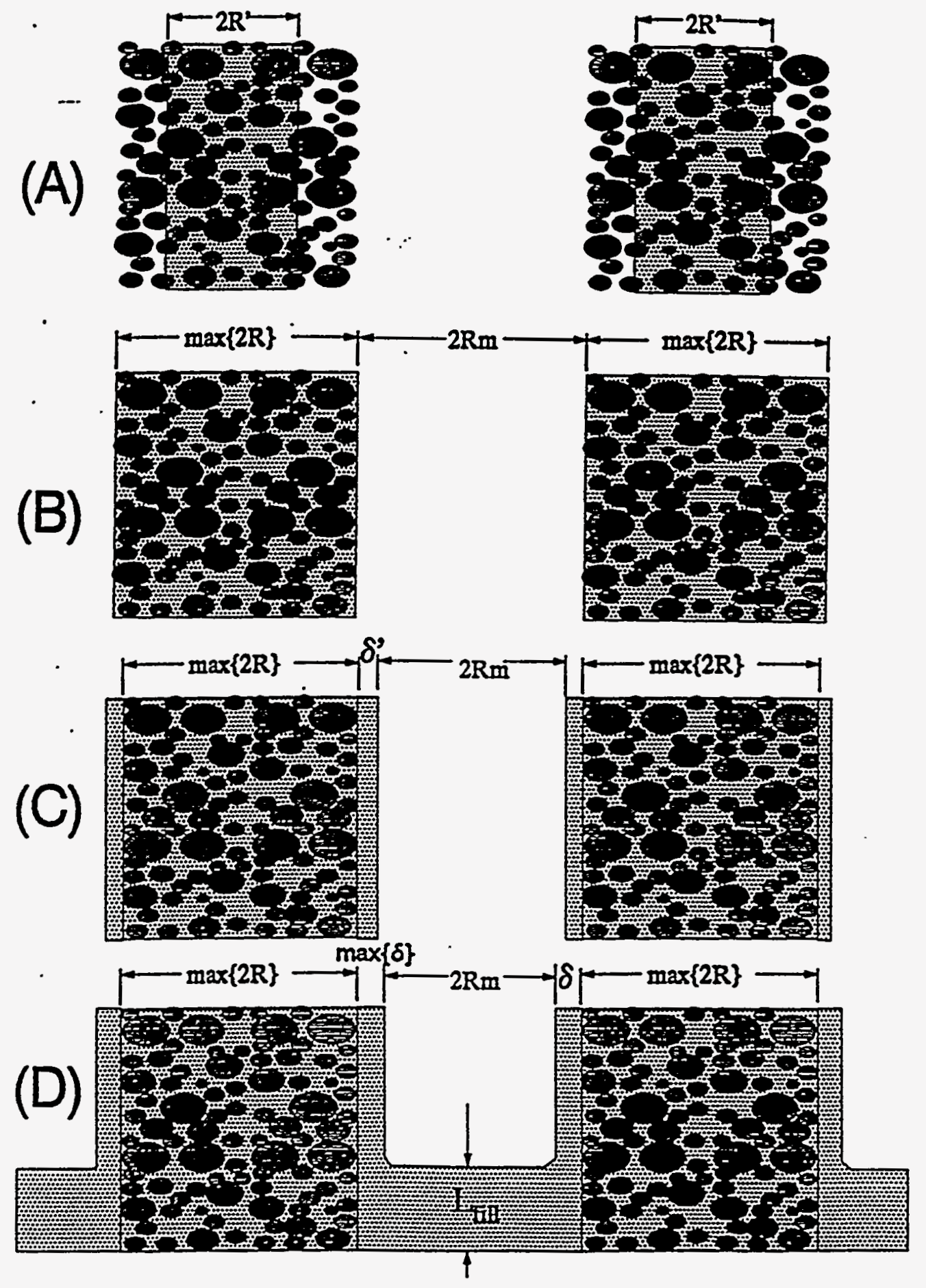

Fig. I Sequence of electrolyte filling for a gas-diffusion porous electrode based on a "fixed-radius agglomerate structure": (A) $\mathrm{V}_{\mathrm{e}}<\max \left\{\mathrm{V}_{\mathrm{e}, \mathrm{dry}}\right\}$, (B) $V_{e}=\max \left\{V_{e, d r y}\right\}$, (C) $\max \left\{V_{e, d r y}\right\}<V_{e} \leq \max \left\{V_{e, f i l m}\right\}$, (D) $V_{e}>$ $\max \left\{V_{e, \text { film }}\right\}$. 


$$
L_{\text {fill }}=L \frac{\left(1-q_{e}\right) V_{e}}{A_{p} L-q_{e} V_{e}-V_{c}}
$$

\subsection{Anode Polarization Characteristics:}

Table 2.2 lists the default (standard case) input parameters for anode used in this : simulation. Hydrogen oxidation is assumed to be a fast reaction with very high intrinsic exchange current density, for example $0.14 \mathrm{~A} / \mathrm{cm}^{2}$; therfore low polarization and a nearly linear relation of polarization-vs- current can be expected. Figs.2 and 3 show that in this case linear characteristics are obtained with various levels of electrolyte filling and even with a ten times. greater $i_{0}^{0}$ value. Thus, the porous MCFC anode, like the porous MCFC cathode, has a quasilinear polarization characteristic [Ref.7].

The optimal electrolyte filling conditions for two values of $i_{0}^{0}$ (see Fig.4) are $\mathrm{V}_{\mathrm{e}}=$ $\max \left\{\mathrm{V}_{\mathrm{e}, \mathrm{dry}}\right\}$ for high $i_{0}^{0}$, but high $\max \left\{\mathrm{V}_{\mathrm{e}}=\mathrm{V}_{\mathrm{e}, \text { film }}\right\}$ for the case with lower $i_{0}^{0}$. Increasing the film thickness (from ștage $B$ to stage $C$ ) increases the diffusion resistance of the film but also the effective ohmic conductance. The latter causes increase of current penetration (i.e., more current generated near the tile ) and consequently reduces the ohmic resistance. However, it also increases the mass transfer resistance caused by the film, but the net effect is a decrease for the low $i_{0}^{0}$ case. On the other hand, for the very high $i_{0}^{0}$ case where most reaction occurs very near the tile even in stage A or stage B (dry agglomerate), no further significant increase of current penetration (or change of current distribution) occurs from stage $B$ to stage $C$. Consequently, the thicker film causes a higher overall voltage loss. Thus, the optimal electrolyte filling for this case (high $i_{0}^{0}$ ) is around stage $\mathrm{B}$.

\subsection{Effect of Anode Agglomerate Size:}

Fig.5 illustrates the effect of electrolyte filling for the same ratio of $R_{m} / R$ (i.e., same porosity, same $\left.\max \left\{\mathrm{V}_{\mathrm{e}, \mathrm{dry}}\right\}\right)$ but different agglomerate size. Very similar shapes are obtained for the reponse curves, but a lower polarization is found when the agglomerate size is smaller. Clearly, small agglomerate size corresponds to a larger number of agglomerate cylinders per unit cross section area. Since the oxidation reaction mostly occurs near the film-agglomerate 


\section{Simulated polarization characteristic}

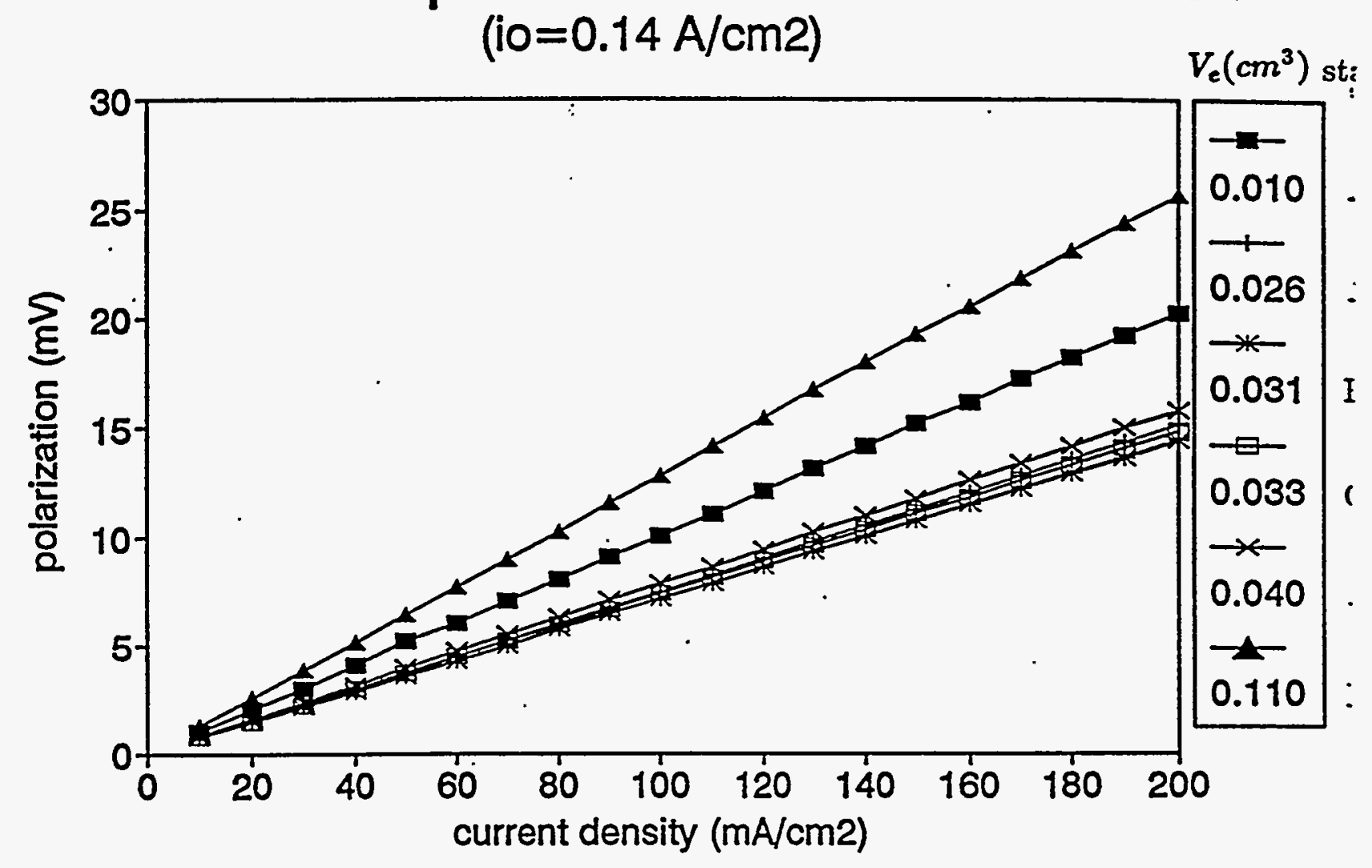

Fig.2 Polarization with $i_{0}^{\circ}$ equaling $0.14 \mathrm{~A} / \mathrm{cm}^{2}$, for variable electrolyte filling $\left(\mathrm{cm}^{3}\right)$. 


\section{Simulated polarization characteristic (io $=0.014 \mathrm{~A} / \mathrm{cm} 2$ )}

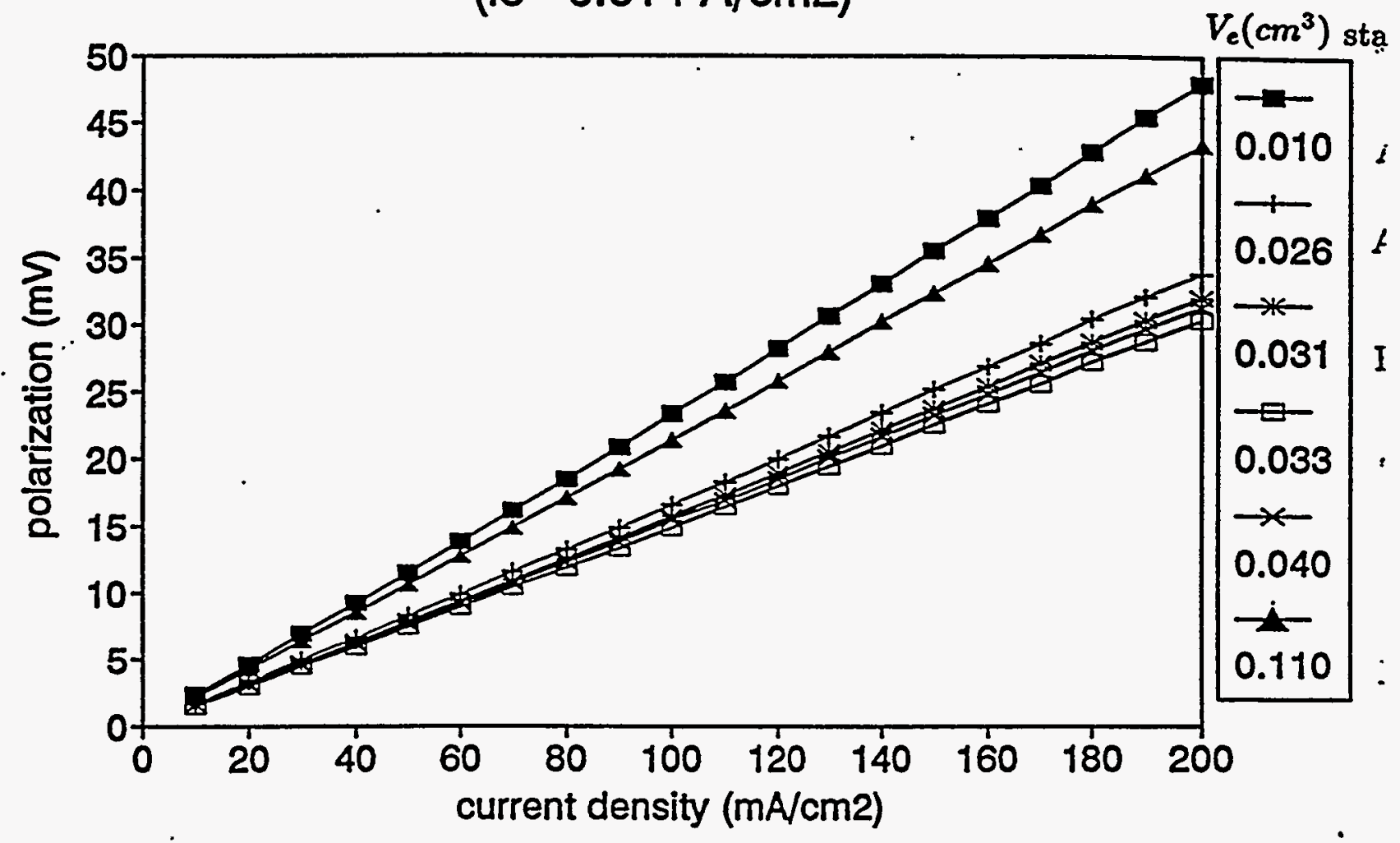

Fig.3 Polarization with $i_{0}^{\circ}$ equaling $0.014 \mathrm{~A} / \mathrm{cm}^{2}$, for variable electrolyte filling $\left(\mathrm{cm}^{3}\right)$. 


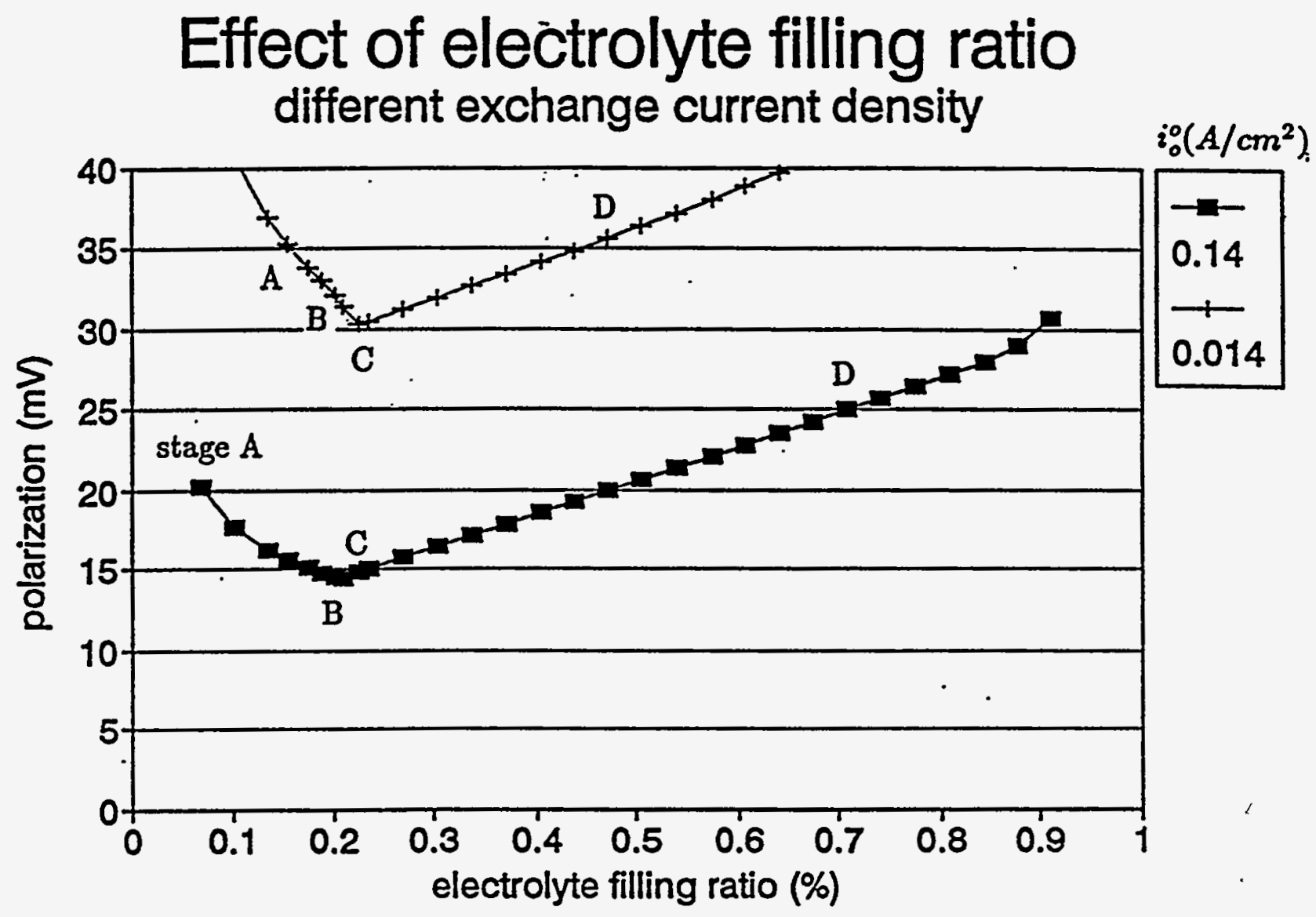

Fig.4 Effect of electrolyte filling ratio on polarization, for various values of intrinsic exchange current density $i_{0}^{\circ}\left(\mathrm{A} / \mathrm{cm}^{2}\right)$. 


\section{Effect of electrolyte filling ratio.}

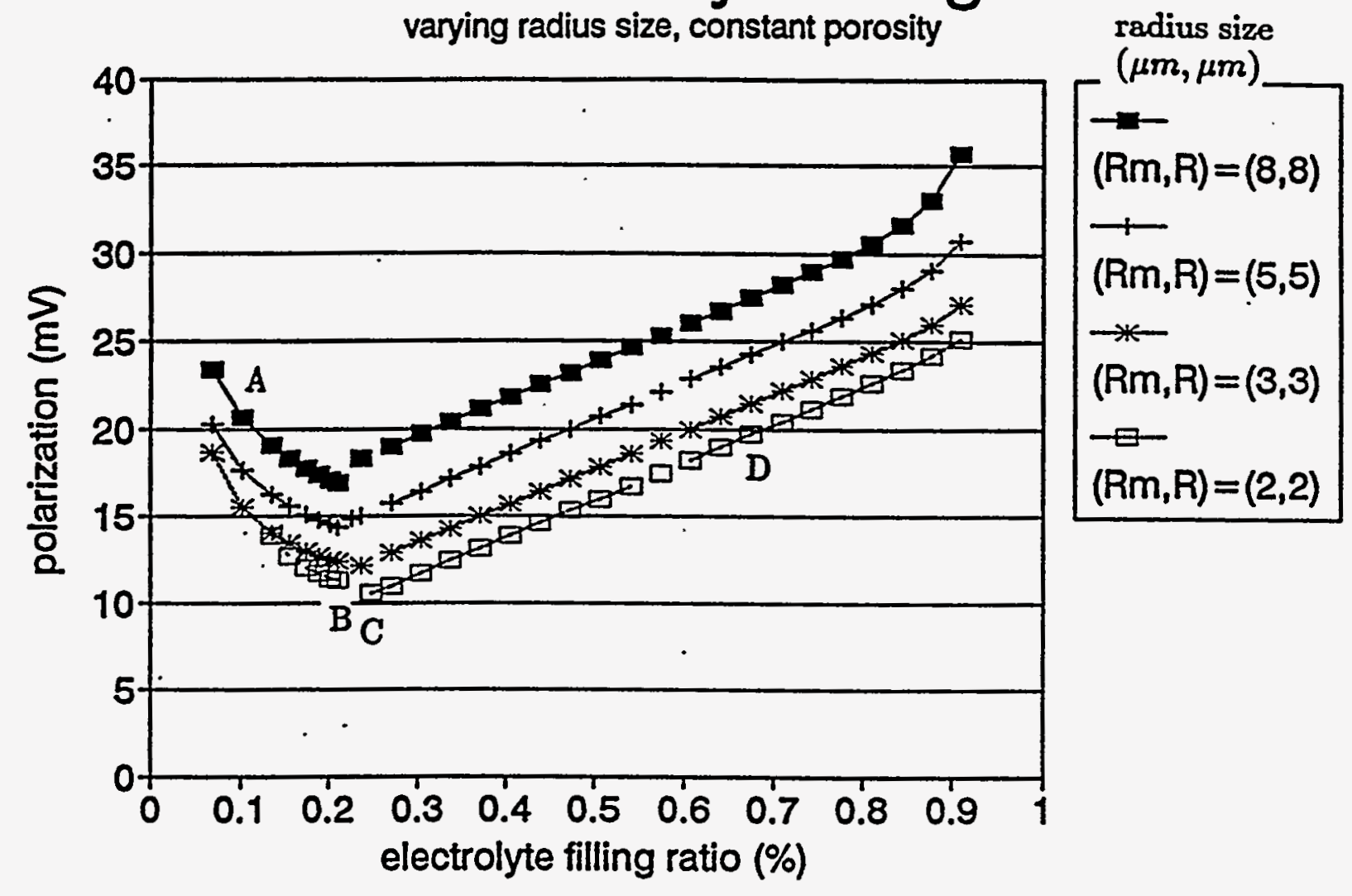

Fig.5 Effect of electrolyte filling ratio on polarization, for various values of macropore radius and agglomerate radius $(\mu \mathrm{m} / \mu \mathrm{m})$. Porosity is constant. 
Table 2.2 Input Parameters för MCFC Anode Simulation.

\section{Standard (default) case}

Temperature (T): 923K

Total pressure (P): $1 \mathrm{~atm}$

Electronic conductivity $(\sigma): 13 \mathrm{ohm}^{-1} \cdot \mathrm{cm}^{-1}$

Ionic conductivity ( $\mathrm{K}): 1.386 \mathrm{ohm}^{-1} \cdot \mathrm{cm}^{-1}$

Maximum film thickness ( $\delta$ ): $0.1 \mu \mathrm{m}$

Electrode thickness (L): $0.08078 \mathrm{~cm}$

Apparent surface area $\left(A_{a}\right): 2.9 \mathrm{~cm}^{2}$

Volume of solid phase $\left(V_{c}\right): 0: 086 \mathrm{~cm}^{3}$

Porosity: 0.5

Electrolyte volume $\left(\max \left\{\mathrm{V}_{\mathrm{e}, \mathrm{dry}}\right\}\right): 0.0311 \mathrm{~cm}^{3}$

Electrolyte volume $\left(\max \left\{\mathrm{V}_{\mathrm{e}, \mathrm{film}}\right\}\right): 0.0335 \mathrm{~cm}^{3}$

Active surface area $\left(A_{s}\right): 329 \mathrm{~cm}^{2} / \mathrm{cm}^{2}$ cross section of electrode

Radius of macropore gas channel $(R m): 5 \mu m$

Radius of agglomerate size: $(R): 5 \mu m$

Reaction orders of $\mathrm{H}_{2}, \mathrm{H}_{2} \mathrm{O}$ and $\mathrm{CO}^{2}$ for hydrogen oxidation: $0.25,0.25,0.25$ (theoretical Ang and Sammells oxidation mechanism)

Intrinsic exchange current density $\left(i_{0}^{0}\right): 0.14 \mathrm{~A} / \mathrm{cm}^{2}$ 
interface, not inside the agglomerate, an electrode with small agglomerate size has a larger and more easily accessible active surface than one with large size agglomerates. However, the ohmic resistance still dominates the overall performance, so the sensitivity to electrolyte filling is similar for various agglomerate sizes.

Fig.6 shows the effect of electrolyte filling ratio when the size of the agglomerate (maximum radius $R$ ) and the radius of the macroporous gas channel $\left(R_{n}\right)$ are varied but the solid volume $\mathrm{V}_{\mathrm{c}}$ is identical. Since the optimal electrolyte filling ratio in the case of high $i_{0}^{0}$ is always . around the transition from stage $B$ to stage $C$, the optimal electrolyte filling ratio shifts from 0.21 for $R_{m} / R$ equaling one, to 0.55 for $R_{m} / R$ equaling 0.625 . The reason for this is, quite simply, that a low ratio of $R_{m} / R$ requires a high value of the elctrolyte filling ratio to reach stage $B$ (complete filling of the agglomerates). This implies that more electrolyte is retained inside the agglomerate in the optimal condition stage $\mathrm{B}$. Thus a higher effective ohmic conductance will result in the condition of optimal electrolyte filling, and a lower polarization can be expected. This is evident from Fig. 6 for the case with $\left(R_{m}, R\right)$ equaling $(5 \mu \mathrm{m}, 8 \mu \mathrm{m}),(3 \mu \mathrm{m}, 5 \mu \mathrm{m})$ or $(2 \mu \mathrm{m}, 3 \mu \mathrm{m})$. Overall, this suggests that a small radius gas channel is desirable and that it is not necessary to have a bimodal pore-size distribution with large mean pore diameter (e.g., around 10 $\mu \mathrm{m}$ ) for the MCFC anode.

\subsection{Effect of Electrolyte Filling on the Cathode:}

A prediction of the effect of electrolyte filling is given in Figure 7, with maximum agglomerate radius $\left(R_{\max }\right)$ equaling $3.5 \mu \mathrm{m}$, radius of macropore $\left(R_{m}\right)$ equaling $3 \mu \mathrm{m}$, and maximum film thickness $0.1 \mu \mathrm{m}$. Table2.3 lists the default (standard case) input parameters for a cathode used in this simulation. In the first stage, not enough electrolyte is present to fill the agglomerate. Part of the catalyst surface is not wetted by electrolyte and is therefore not active. Increasing electrolyte filling increases the volume fraction of wetted catalyst surface $\left(q_{c}\right)$, and this leads to lower polarization. Once the "active radius" $R$ ' of agglomerate reaches $R_{\max }$, the additional electrolyte will form an electrolyte film around the agglomerate(stages $B$ and $C$ ). This increases the voltage loss since the film thickness increases, thereby increasing diffusion resistance across the film. However, a maximum film thickness, $\delta$, will be reached, beyond which the excess electrolyte starts to fill the macropore near the tile side (stage D). Increasing the 


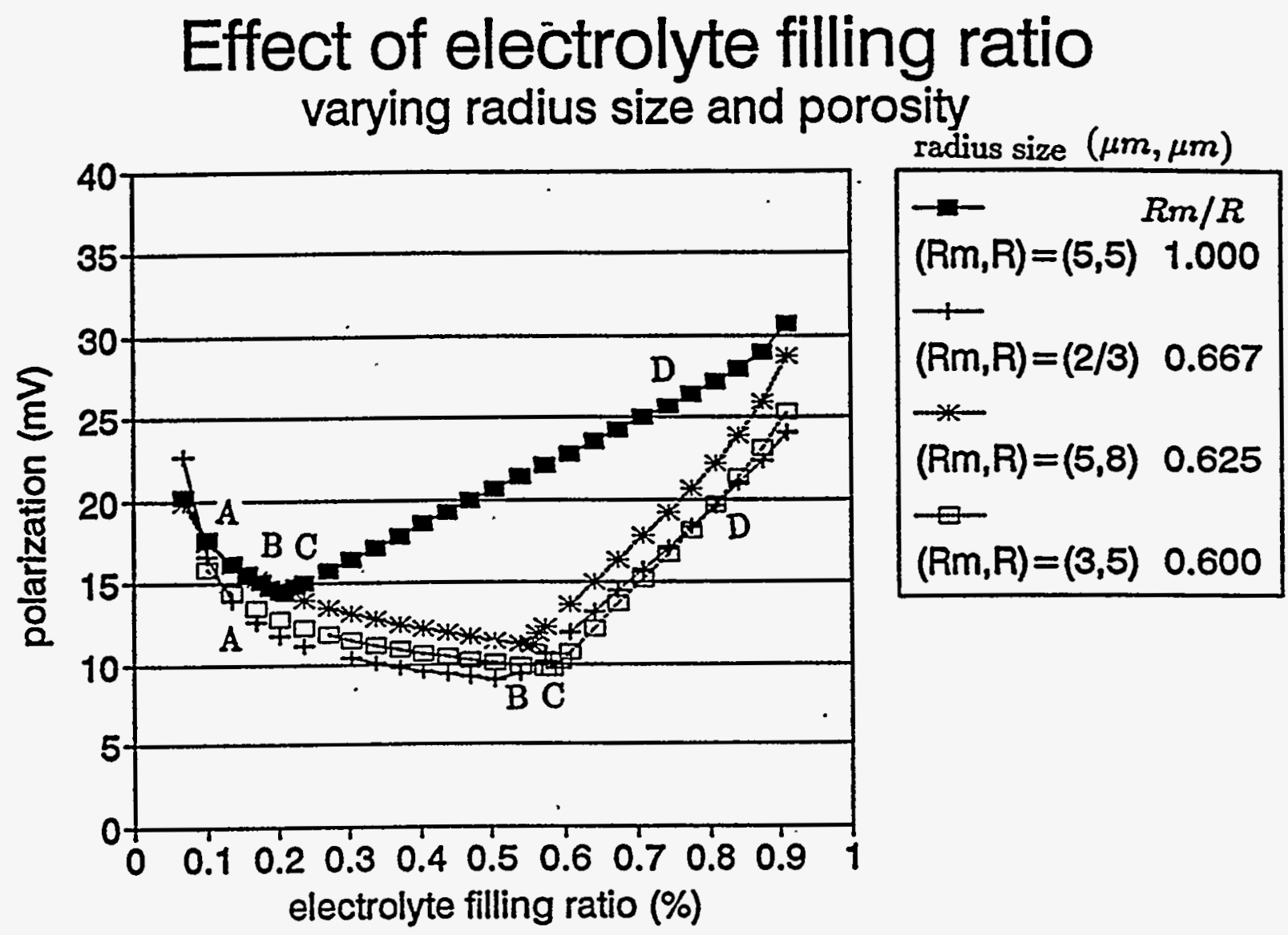

Fig.6 Effect of electrolyte filling ratio on polarization, for various values of macropore radius and agglomerate radius $(\mu \mathrm{m} / \mu \mathrm{m})$. Porosity is variable. 


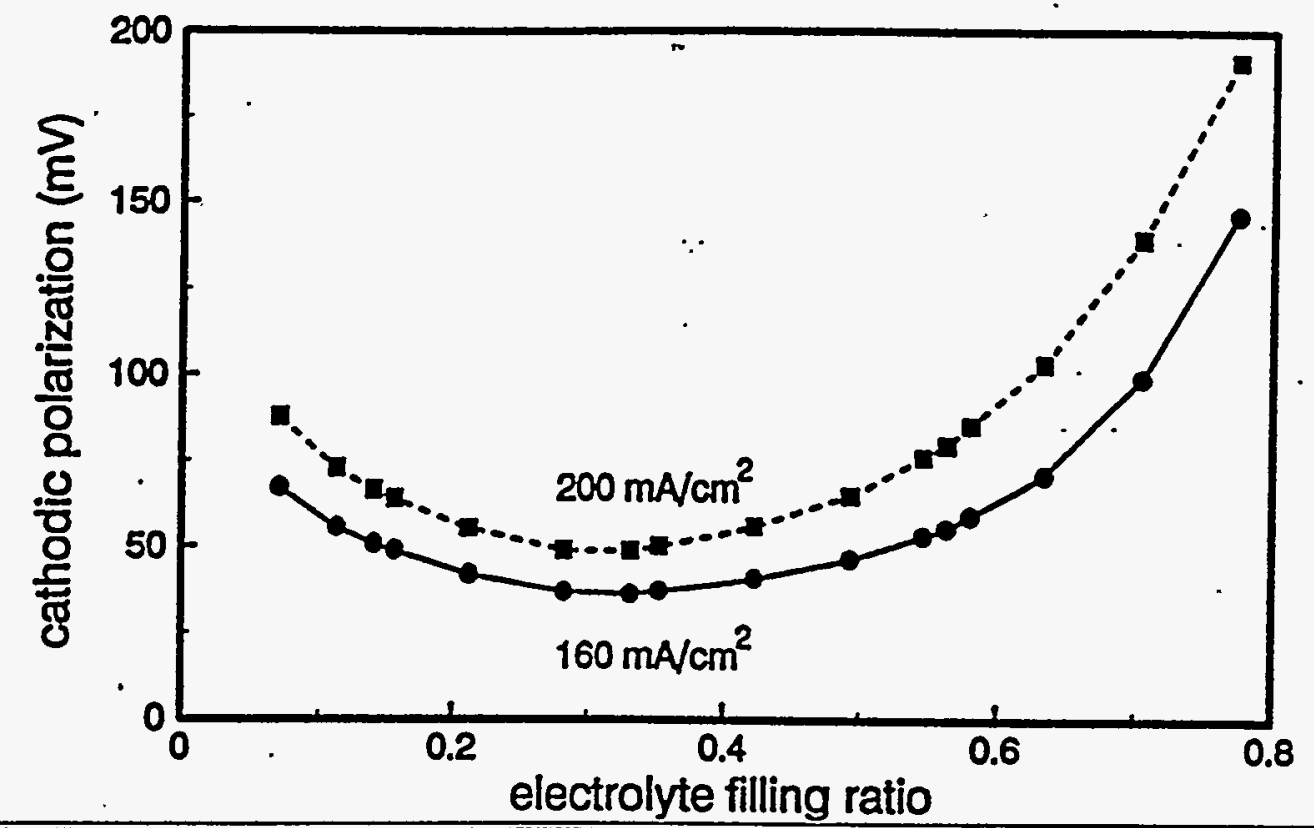

\begin{tabular}{lllllllll}
\hline \hline$i_{0}^{o}$ & $\sigma$ & $\kappa$ & $R_{m}$ & $A_{p}$ & $L$ & $V_{c}$ & $\max \{V e\}$ & $A_{s}$ \\
$A / m^{2}$ & $\frac{1}{\text { ohm.m }}$ & $\frac{1}{\text { ohm.m }}$ & $\mu m$ & $m^{2}$. & $\mu m$ & $m^{3}$ & $m^{3}$ & $m^{2} / m^{2}$ \\
\hline 10 & 3300 & 142 & 3 & 0.00029 & 400 & $4.5 \times 10^{-8}$ & $7.1 \times 10^{-8}$ & 319 \\
\hline
\end{tabular}

\begin{tabular}{cclllllll}
\hline \hline $\mathrm{Ve}\left(\mathrm{m}^{3}\right)$ & ratio & $\mathrm{R}(\mu \mathrm{m})$ & $q_{\mathrm{c}}$ & $\delta(\mu m)$ & $q_{e}$ & $L_{\text {fill }}(\mu \mathrm{m})$ & $\eta_{160}(\mathrm{mV})$ & $\eta_{200}(\mathrm{mV})$ \\
\hline $5 \times 10^{-9}$ & 0.07 & 1.75 & 0.25 & & & & 67.0 & 87.4 \\
$8 \times 10^{-9}$ & 0.11 & 2.21 & 0.40 & & & & 55.3 & 72.4 \\
$10 \times 10^{-9}$ & 0.14 & 2.48 & 0.50 & & & & 50.5 & 66.1 \\
$15 \times 10^{-9}$ & 0.21 & 3.03 & 0.75 & & & & 41.7 & 55.0 \\
$20 \times 10^{-9}$ & 0.28 & 3.50 & 1.0 & 0.0 & & & 36.8 & 48.7 \\
$23.5 \times 10^{-9}$ & 0.33 & 3.50 & 1.0 & 0.1 & 1.0 & & 36.2 & 48.5 \\
$25 \times 10^{-9}$ & 0.35 & 3.50 & 1.0 & 0.1 & 0.94 & 10 & 37.0 & 49.9 \\
$30 \times 10^{-9}$ & 0.42 & 3.50 & 1.0 & 0.1 & 0.78 & 60 & 40.7 & 55.7 \\
$35 \times 10^{-9}$ & 0.49 & 3.50 & 1.0 & 0.1 & 0.67 & 100 & 46.2 & 64.8 \\
$40 \times 10^{-9}$ & 0.56 & 3.50 & 1.0 & 0.1 & 0.59 & 140 & 55.2 & 79.4 \\
$45 \times 10^{-9}$ & 0.63 & 3.50 & 1.0 & 0.1 & 0.52 & 180 & 70.8 & 103.1 \\
$50 \times 10^{-9}$ & 0.70 & 3.50 & 1.0 & 0.1 & 0.47 & 220 & 98.9 & 139.5 \\
$.55 \times 10^{-9}$ & 0.77 & 3.50 & 1.0 & 0.1 & 0.43 & 270 & 146.4 & 191.1 \\
\hline
\end{tabular}

Figure 7. Effect of electrolyte filling ratio of MCFC cathode 
Temperature (T) : $923 \mathrm{~K}$

Total pressure( $(\mathrm{P}): 1 \mathrm{~atm}$

Cathode electrode thickness $(\mathrm{L}): 0.0409 \mathrm{~cm}$

Cathode mean pore diameter $\left(\mathrm{d}_{\mathrm{p}}\right): 7 \mu \mathrm{m}$

Cathode porosity $(\varepsilon): 0.784$

Fraction of porosity in cathode macropore $(f): 0.9$

Cathode active surface area $\left(A_{s}\right): 217 \mathrm{~cm}^{2}$ per $\mathrm{cm}^{2}$ cross section of electrode

Cathode film thickness : $0.1 \mu \mathrm{m}$

Intrinsic current density $\left(\mathrm{I}_{0}{ }^{0}\right): 0.00267 \mathrm{~A} / \mathrm{cm}^{2}$ (super oxide mechanism)

$0.0082 \mathrm{~A} / \mathrm{cm}^{2}$ (peroxide mechanism)

$0.0267 \mathrm{~A} / \mathrm{cm}^{2}$ (oxygen first order mechanism) 
electrolyte filling then decreases the effective electrode thickness, and the polarization will increase. Since the effective electrode thickness is reduced, so is the apparent active surface area. An optimum electrolyte filling ratio at $30 \%$ is predicted for this condition.

\subsection{Effect of Cathode Agglomerate Size:}

In Figure 8, a high electrode conductivity $\left(\sigma=33 \mathrm{ohm}^{-1} \mathrm{~cm}^{-1}\right)$ is assumed,and the major voltage loss may be caused by the electrolyte ohmic resistance, kinetic activation resistance or mass transfer resistance.Comparing for the same size of macropore gas channel,a small radius of the agglomerate corresponds to larger numbers of agglomerates per unit cross section area, a higher volume fraction of macropore gas channel and a smaller micro-porosity inside the agglomerate.Overall, these will lead smaller apparent electrolyte conductivity, but larger apparent electronic conductivity since the effective conductivity depends on the1.5 power of the conducting volume fraction. In this case, the electrolyte ohmic resistance is major contribution of voltage loss,but the electronic ohmic resistance is not, therfore, higher polarization is observed at low $\max \{R\}$.

Figure 8 shows a steep increase at the side of too much "excess"electrolyte filling is shown and an optimum electrolyte filling ratio can be found at the end of stage $C$. At stage $A$, the active surface is increased by increasing the electrolyte filling and the increasing amount of electrolyte filling dramatically increases the apparent electrolyte conductivity. Both effects are larger than the increasing mass transfer resistance, and a sharp decrease of cathodic polarization is expected. It is also note-worthy that the distribution of the cathodic potential driving force is more uniform due to larger electrolyte conductivity, which implicitly leads the whole process to be kinetically controlled, like in the case of a large active-surface planar electrode.

From stage $B$ to $C$, film formation provides the better ionic conductivity. This effect leads to polarization decrease, even though the mass transfer resistance is increasing with increasing film thickness. At stage $D$, increasing the "excess" electrolyte filling decreases the effective thickness but does not increase the polarization sharply at the beginning. At this stage,a shorter effective electrode thickness requires a more uniform potential distribution and the active surface at the center of the agglomerate can be used to compensate the reduced effective electrode thickness, as the polarization will increase steeply if there is not enough active surface. 


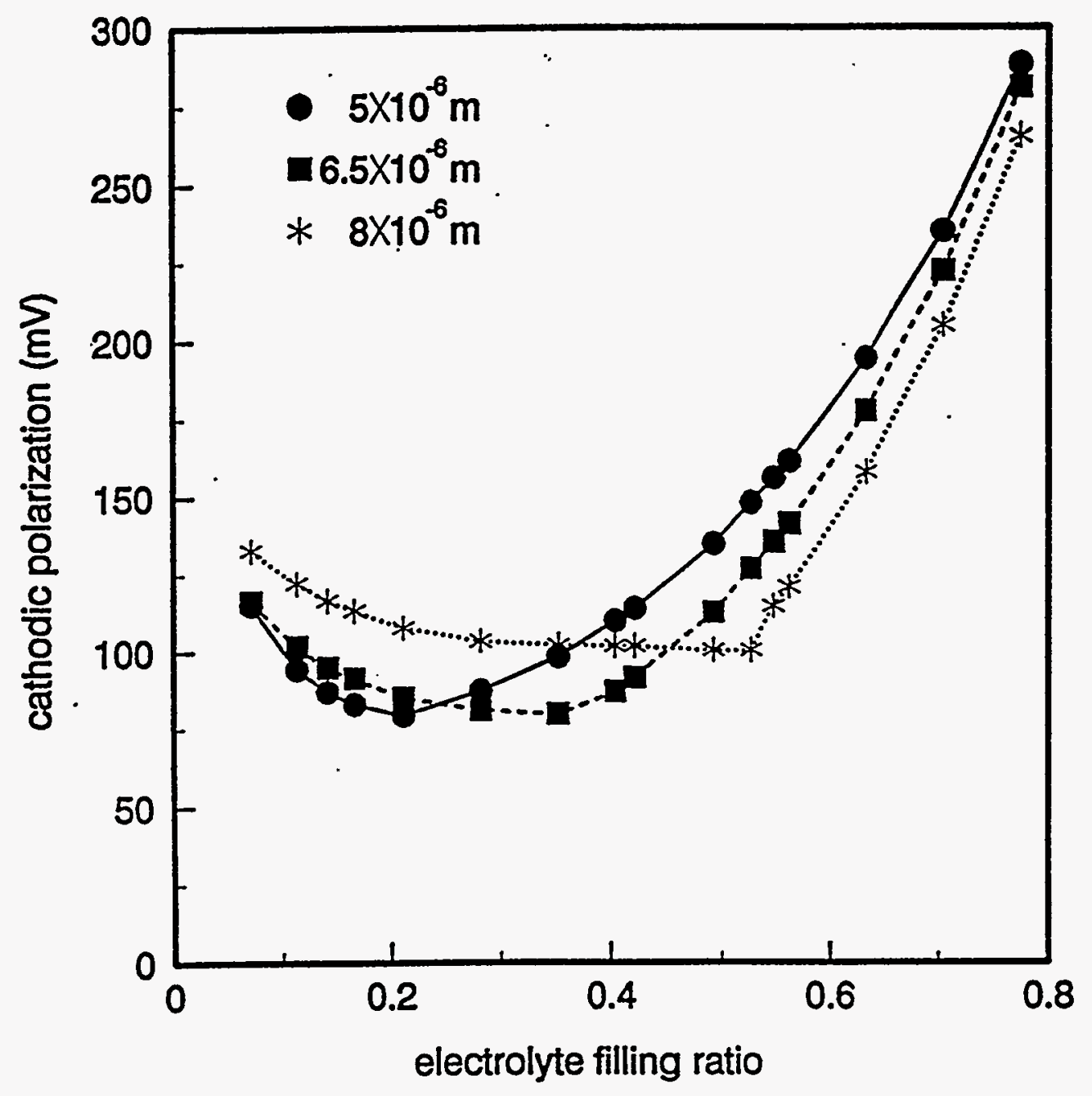

Figure 8. Effect of electrolyte filling ratio of a cathode for various values of maximum agglomerate size 


\subsection{Conclusions}

1. The different models compared above (Yuh and Selman, Kunz et al.) are based on the assumption that the microporous agglomerates can be treated as pseudo-homogeneous. In Fig. 2.4, the reaction zone inside the agglomerate is of approximately the same thickness as the diameter of the individual particles forming the agglomerate. Therefore, the pseudohomogeneous assumption is doubtful. Furthermore, the concept of an "exterior agglomerate surface" depends on the shape of the agglomerate particles and has an unprecise meaning. None of the above models takes into account the restricted percolation of gas into the electrode when the gas porosity is low. The latter effect will be of critical importance at high degrees of electrolyte fill.

Consequently, the agglomerate model for the MCFC cathode gives more reasonable results if the exterior agglomerate surface area is explicitly taken into account. A thin-film model with a roughness factor for the electrode surface appears to be as good a practical model as the agglomerate model.

2. A beginning has been made with this extension of the filmed agglomerate model, and some initial results have been obtained. From concurrent work in Sweden [Ref. 5] and the Netherlands [Ref. 6] we conclude that it is possible and desirable to use more refined models for the structure of the porous electrode and of the liquid-gas interface in the electrode pores. For this purpose we have obtained a finite element code (Topaz, made available by courtesy of Lawrence Livermore Laboratory) which can be a powerful tool in modeling both porous electrodes and entire cells. However, thus far our laboratory lacks a workstation that has the capacity necessary to accommodate this program. With the help of a workstation and the Topaz program, we expect to be able to continue and successfully complete the performance modeling for high power density. 


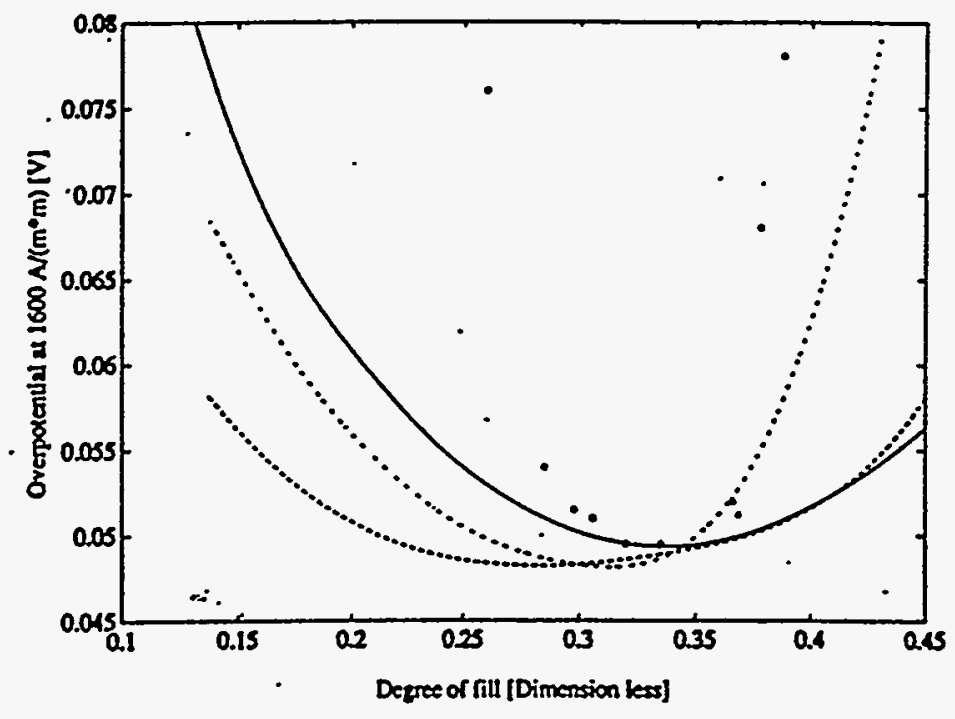

Fig 2-4. Comparison between the different models. Solid line : modified agglomerate model with growing radius; dashed line: the partially drowned agglomerate model; dot-dashed line: the chain of spherical agglomerate model 
3. Overall, high $i_{0}^{0}$ causes anode electrode performance to be dominated by ohmic resistance, The optimal electrolyte filling ratio corresponds to the transition from stage B to C. A small porosity is preferable, in spite of gas-phase resistance and internal reforming (whose effects have been neglected thus far). Small electrode thickness and solid volume provide better performance. However, it must be noted that, though the anode may be used as an electrolyte reservoir, too dry an agglomerate (Stage A) or too much electrolyte filling (stage D), which may occur in long-term cell operation, can lead to catastrophic cell failure due to tremendously increasing anode polarization if the electrode thickness is too small and there is not enough solid volume (i.e., insufficiently electrochemically active surface are).

The sensitivity of polarization to electrolyte filling is greater in the porous anode than in the porous cathode. However, the absolute value of polarization compared to that of the cathode is small. This indicates that the optimal design of the anode must be focused on how to maintain good or very good electrode performance during long-term cell operation

\section{TASK 3. CATHODE RESPONSE MODEL}

\subsection{Introduction}

Under this task a large number of stationary and dynamic measurements have been made, by means of a 3-cm lab-scale MCFC. Performance at very low $\mathrm{CO}_{2}$ partial pressures is compared with that of standard oxidant composition. The results confirm incomplete data obtained earlier on lab and bench scale $\mathrm{MCFCs}$ using low- $\mathrm{CO}_{2}$ oxidant. Low $\mathrm{CO}_{2}$ partial pressure is necessary to suppress cathode dissolution and increase cell life-time; hence MCFC developers currently aim to work with as low a $\mathrm{CO}_{2}$ partial pressure as feasible. However, operating the fuel cell at $\mathrm{CO}_{2}$ partial pressures below $0.05 \mathrm{~atm}$ lowers the cell performance. This is illustrated in Fig. 3.1.

The role of electrolyte filling is also of importance. Fig. 3.2, from work performed under this Task, shows that the optimal range of electrolyte filling becomes narrower as the current density is increased. This effect is even more pronounced at low $\mathrm{CO}_{2}$ partial pressures. 


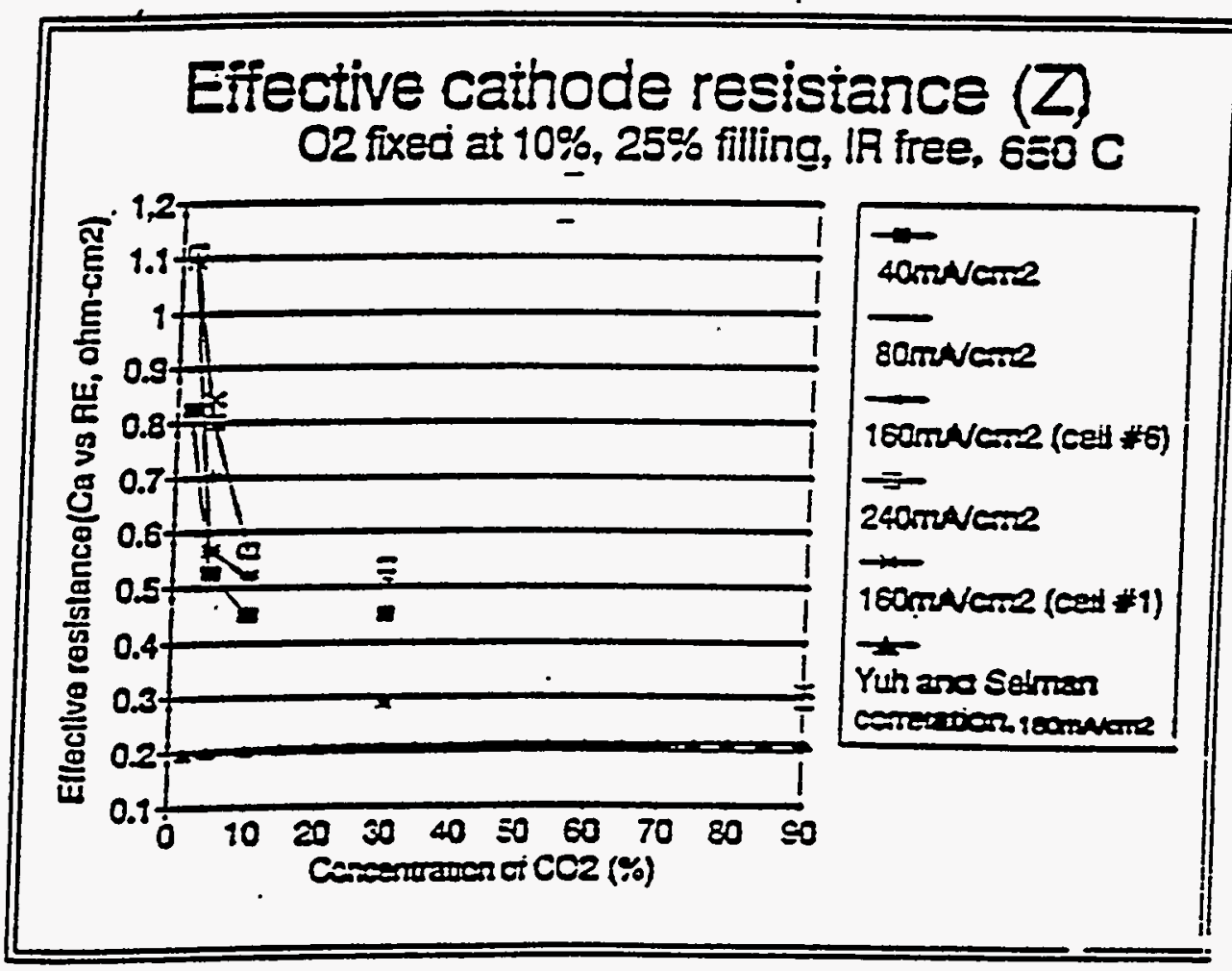

Fig.3.1.Effective cathode resistance of a porous $\mathrm{NiO}$ cathode in a $3 \mathrm{~cm}^{2}$ laboratory cell, under standard and low $\mathrm{CO}_{2}$ partial pressures (total pressure $1 \mathrm{~atm}$ ) 


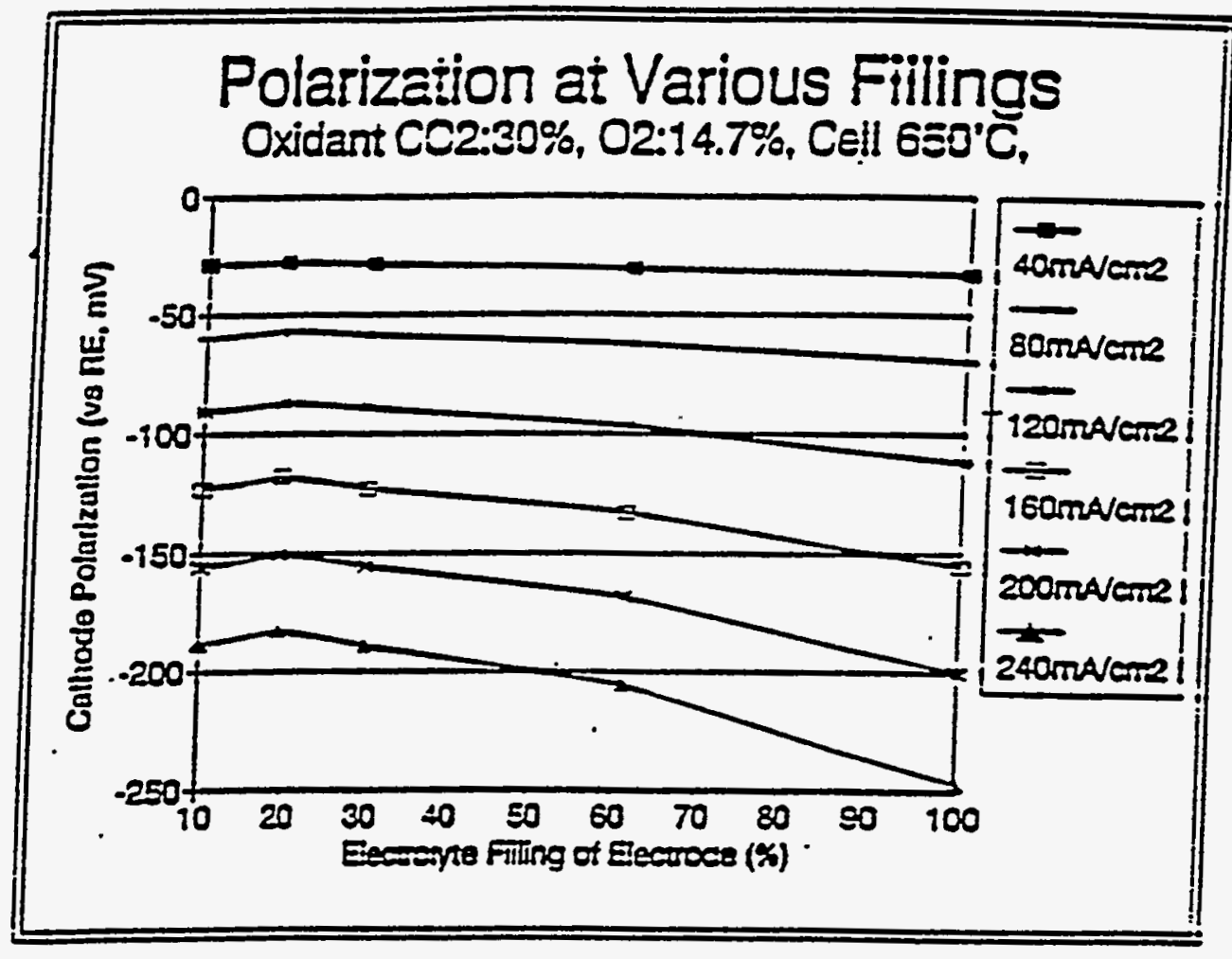

Fig.3.2.Polarization at various electrolyte filling ratios, under standard $\mathrm{CO}_{2}$ partial pressure. 
The role of electrolyte filling is also of importance. Fig. 3.2, from work performed under this Task, shows that the optimal range of electrolyte filling becomes narrower as the current density is increased. This effect is even more pronounced at low $\mathrm{CO}_{2}$ partial pressures.

An especially interesting finding, first observed by Yuh [Ref. 7] is that the dynamics of the cathode reaction are affected by low- $\mathrm{CO}_{2}$ partial pressures. Performance recovers very slowly after oxidant composition is returned to normal $\mathrm{CO}_{2}$ levels.(Fig. 3.3) This suggests that the reaction mechanism is completely changed.

\subsection{Objectives}

The objectives of this task are: (1) to analyze the porous electrode kinetics; (2) to predict performance and voltage loss under low- $\mathrm{CO}_{2}$ conditions; (3) to explain the sluggish cathode dynamics in terms of a changed reaction mechanism. Preliminary to an analysis by porous electrode kinetics, the performance data in our work are being correlated. Correlation developed in previous work [Ref. 8] does not predict satisfactorily cathode performance in the low- $\mathrm{CO}_{2}$ range.

The measurements made to date will be reported in detail in a forthcoming M.S. thesis [Ref. 10]. They include not only stationary polarization measurements, but dynamic measurements (potential relaxation) and $\mathrm{AC}$ impedance measurements made in conjunction with the stationary polarization measurements. As in previous work in this laboratory [Ref. 2], the AC impedance data give useful insight into the balance between ohmic resistance, slow kinetics and diffusion resistance at increasingly small $\mathrm{CO}_{2}$ partial pressures. In addition, the role of the electrolyte filling ratio (ratio of electrolyte-filled pore volume to total porosity) is clearly much stronger than usual. These factors together indicate that at low $\mathrm{CO}_{2}$ partial pressure the operation of the cathode is limited by a combination of $\mathrm{CO}_{2}$ depletion and slow kinetics of the oxide- $\mathrm{CO}_{2}$ recombination step (reaction 1, discussed earlier).

This interpretation would be consistent with our findings in the wetting angle measurements (Task 1). However, further evidence is needed to support this conclusion and, especially, to determine the role of solid oxide layers, if any, formed on the $\mathrm{NiO}$ particles under 
Potensiai Relaxarion upon Oxidant change

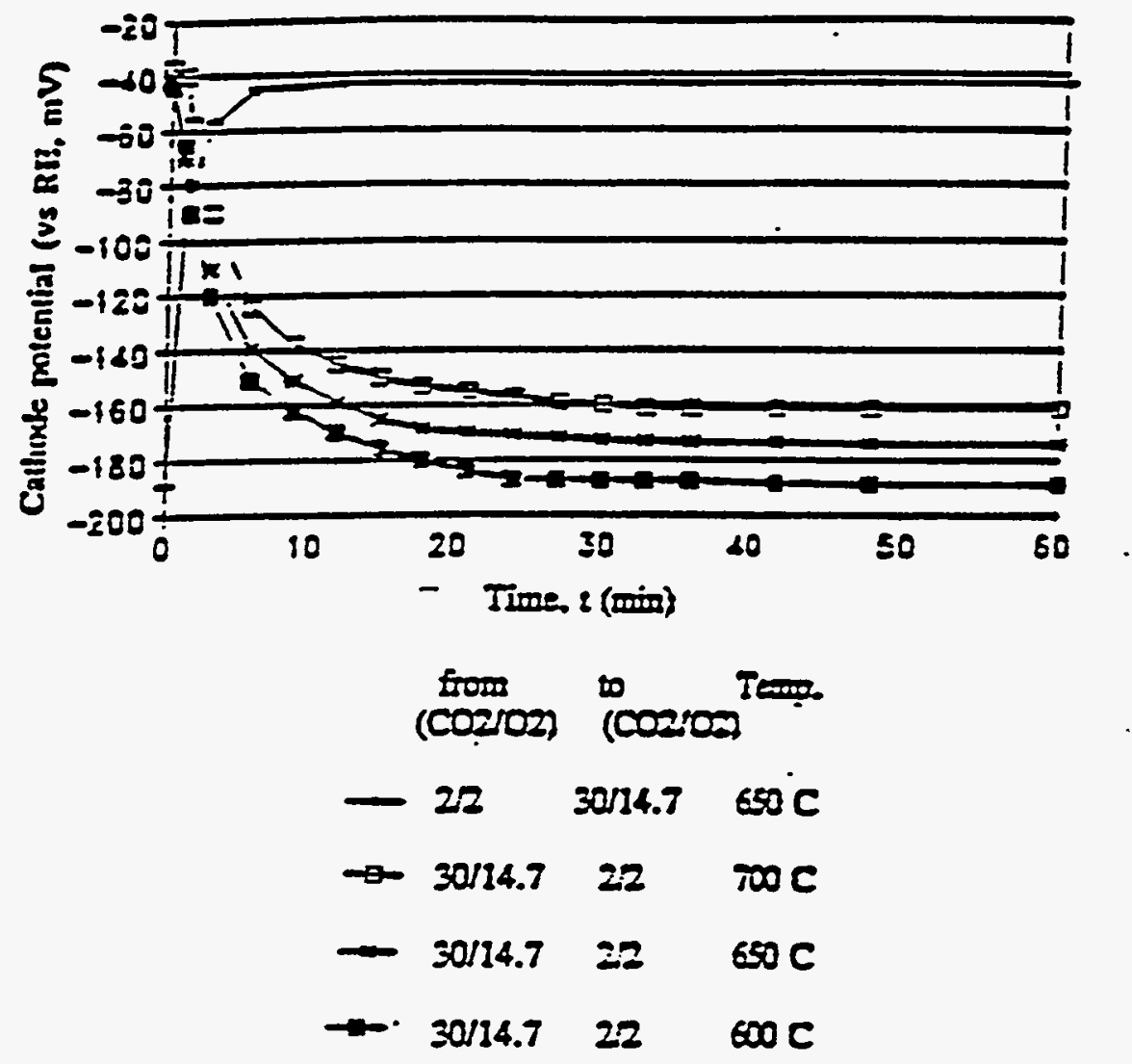

Fig.3.3.Potential relaxation upon change of oxidant composition. 
these conditions. Furthermore, a quantitative model of the working of a low- $\mathrm{CO}_{2}$ cathode is needed to predict performance under changes of gas composition, temperature, etc.

\section{TASK 4. METAL SOLUBILITY IN CARBONATES}

\subsection{Introduction}

The objective of this task is to understand the behavior of pure metals and metal alloys (such as stainless steels) in contact with molten carbonate, under MCFC conditions. A specific . concern of great practical importance is the solubility of the $\mathrm{NiO}$ cathode and the tendency of MCFC cells having NiO cathodes to short out in long-term operation. This problem is described in more details in Section 4.2 , which analyzes the processes leading shorting systematically. In the following section (4.3) the oxidation and lithiation process is experimentally investigated. Section 4.4 deals specifically with the details of the shorting behavior and Section 4.5 with strategies to prevent it. The solubility of nickel as well as other metals is investigated by methods presented in more detail in section 4.6.

\subsection{NiO Dissolution and Cell Shorting: Overview}

The instability of construction materials and corrosive action of the reacting chemical species are life-limiting factors for the MCFC. The basic requirements for MCFC cathode materials are stability, conductivity and suitable pore structure. The above performance and stability requirements are satisfied by lithium-doped $\mathrm{NiO}$ electrodes except for the solubility in the electrolyte. The dissolution of the lithiated-NiO cathode into the electrolyte and the subsequent precipitation of metallic nickel in the electrolyte tile are coupled processes. Because of their complexity they must be analyzed together, from both experimental and theoretical points of view. 
Experience with laboratory cells and scaled-up cells in MCFC stacks indicates that formation of dispersed nickel particles precipitated in the electrolyte matrix, from cathode to anode side, can degrade cell performance and shorten cell life.' Several partial processes constitute this performance degradation process. NiO dissolution, nickel precipitation and shorting phenomena are connected and must be evaluated together, to arrive at possible solutions for the overall performance and stability problem. The causative mechanisms include dissolution, migration, deposition and electronic conduction processes. All these processes are coupled to electrochemical reactions and transport processes within the MCFC.

The primary experimental concern in this fuel cell system is that of designing and operating the cell in such a manner that the rate of cathode degradation is minimized and cell endurance is assured. Slow dissolution of the $\mathrm{NiO}$ cathode and reductive deposition of the $\mathrm{NiO}$ as metallic nickel can cause formation of a conducting path in the electrolyte tile and lead to $\mathrm{a}$. short circuit. An attack on this problem is made more difficult by the fact that the various MCFC developers are not in agreement that shorting actually occurs, or even can occur, in their stacks. Most developers agree that $\mathrm{NiO}$ dissolution takes place, even though it can be mitigated significantly by increasing the basicity of the electrolyte in the cathode or in the electrolyte matrix. There is also reason to give credence to the suggestions made by some developers that the integrity and uniformity of the electrolyte matrix plays a significant role in the occurrence or non-occurrence of actual shorts. Table 4.1 is an attempt to summarize the known and unknown factors in the dissolution/shorting issue.

Two simultaneous reactions occur at the $\mathrm{NiO}$ cathode. The overall reaction is the result of a corrosion couple in which $\mathrm{NiO}$ is anodically dissolved and oxygen is cathodically reduced. $\mathrm{NiO}$ dissolves into carbonate melt by an acidic flux mechanism. As long as oxygen partial pressure is low, the rate of dissolution is proportional to $\mathrm{CO}_{2}$ pressure. There is some indication that dissolved nickel is present as $\mathrm{Ni}^{2+}$. The first step in this acidic dissolution mechanism for the formation of $\mathrm{Ni}^{2+}$ ions is, therefore

$$
\mathrm{NiO}=\mathrm{Ni}^{2+}+1 / 2 \mathrm{O}_{2}+2 \mathrm{e}^{-}
$$


Table4.1. Known and unknown factors in NiO dissolution and shorting of MCFC cells or stacks.

\author{
DISSOLUTION \\ KNOWN FACTORS \\ ACIDIC / BASIC DISSOLUTION BEHAVIOR \\ PARTIAL PRESSURE OF $\mathrm{CO}_{2}$ \\ ELECTROLYTE ADDITIVES (ACIDITY/BASICITY) \\ UNKNOWNFACTORS \\ EFFECT OF LITHIATION PROCESS \\ EFFECT OF CURRENT DENSITY \\ EFFECT OF CRACKS AND VOIDS IN THE MATRIX \\ LONG TERM EFFECT OF ADDITIVES \\ CURRENT COLLECTOR/ CATHODE / MATRIX LONG TERM INTERACTION \\ MOTION AND DISSOLUTION OF PARTICLES IN THE MATRIX $\cdot$
}

SHORTING

KNOWNFACTORS

MATRIX THICKNESS

$\mathrm{CO}_{2}$ PRESSURE

UNKNOWN FACTORS

CONDUCTING LINK BETWEEN CATHODE AND ANODE

CRITICAL AMOUNT OF NICKEL IN THE TILE

STRUCTURAL DEFECTS IN THE MATRIX

ADDITIVES

MOTION AND DISSOLUTION OF PARTICLES IN THE MATRIX

EFFECT OF TILE REACTIONS $\quad\left(\mathrm{H}_{2} \mathrm{O}\right.$ formation) 
which is coupled with the main reduction reaction:

$$
1 / 2 \mathrm{O}_{2}+\mathrm{CO}_{2}+2 \mathrm{e}^{-} \rightarrow \mathrm{CO}_{3}^{2-}
$$

Overall this is a mixed-potential corrosion process, e.g., slow dissolution reaction in the anodic sense with the oxygen reduction reaction in the cathodic sense.

$$
\mathrm{NiO}+\mathrm{CO}_{2} \rightleftarrows \mathrm{Ni}^{2+}+\mathrm{CO}_{3}^{2-}
$$

The dissolution level of nickel oxide may be reduced by operating the cathode at low $\mathrm{CO}_{2}$ partial pressure but too low a $\mathrm{CO}_{2}$ partial pressure causes a negative effect on cell performance as Eqn. 5 suggests. It has also been reported that the solubility of $\mathrm{NiO}$ in carbonate environment is considerably reduced by the addition of $\mathrm{Mg}^{2+}, \mathrm{Ca}^{2+}, \mathrm{Sr}^{2+}$ and $\mathrm{Ba}^{2+}$ cations [Ref. 6 ]. The effect of additives on the oxidation behavior of $\mathrm{NiO}$ in carbonate melts is being investigated in this project. The effect of additives on NiO solubility becomes less if the additives have a tendency to segregate toward the anode.

The dissolution-deposition process also causes structural changes in the cathode due to loss of material and electrolyte displacement toward the matrix. However, decrease of cathode performance is not so much due to the depletion of active cathode material, as to the accumulation of metallic nickel in the tile.

The strategy adopted in attacking this challenging problem is to distinguish the following separate steps in the process:

(1) dissolution of $\mathrm{NiO}$ and diffusion/migration of dissolved nickel into the tile;

(2) reduction of dissolved nickel and precipitation of Ni particles;

(3) growth, agglomeration, and convection of Ni particles;

(4) formation of electrical conduction paths across the matrix.

At this advanced stage of MCFC development, much is known about stage (1), due to the work of many developers and several university or National Laboratory based groups. Models 
for the thermodynamics of $\mathrm{NiO}$ solubility and the transport of dissolved nickel are available (Ota et al. [Ref. 12], Shores et al. [Ref. 11], Veldhuis et al. [Ref. 13]). Therefore, our attention has been mainly directed at the other steps. During the report period we have concentrated on steps 2 and 3 and studied the behavior of nickel metal during oxidation and dissolution. In the next phase, we will study the reduction of dissolved nickel.

\subsection{Nickel Oxidation and Lithiation}

Oxidation/lithiation requires understanding of the solid-state behavior as a $\mathrm{NiO}$ electrode is formed. Oxidation of the nickel electrode reduces its conductivity. By doping the oxide electrode with lithium ion, its conductivity is increased. Therefore, the in situ formation of the cathode involves the reaction of nickel with oxygen, coupled with lithiation. The atomic level structure of the cathode is an important factor in the performance and life-time of a cell.

The initial oxidation and spontaneous lithiation of a nickel electrode are part of a corrosion reaction taking place. It is also observed that a dissolution process is taking place during the beginning of this in-situ oxidation process (or, alternatively, breaking of oxide species from the electrode surface.). At the beginning of the experiment, the electrode is partially immersed into the carbonate electrolyte and oxidant gas is sent over the electrolyte melt. The initial surface oxidation of nickel is completed within an hour. At the end of the process, the differences in surface appearance of immersed and non-immersed parts of the electrode are easily distinguished.

Oxidation of the nickel electrode in the carbonate environment takes place under open circuit conditions. A NiO layer grows on nickel by the simultaneous diffusion of nickel ions via cation vacancies and of electron holes. Oxygen incorporation into nickel oxide gives rise to cation vacancies, having a positively charged site, and electron holes. If defects formed in the above process undergo no further reaction, self-diffusion takes place, i.e., migration of cation vacancies and migration of holes which give rise to electrical conductivity. When given a sufficient energy these positive holes may cause $\mathrm{Ni}^{3+}$ ions to be formed. In order to create a high $\mathrm{Ni}^{3+}$ concentration $\mathrm{NiO}$ is doped with lithium. During oxidation $\mathrm{Li}^{+}$has to diffuse into the oxide therefore the time for the lithiation process depends on thickness of the electrode. 
$\mathrm{NiO}$ is a metal deficit, p-type semiconductor. Its electrical conductivity is dependent on oxide concentration. Oxygen can react with $\mathrm{NiO}$ to form defects that give rise to diffusion and electrical conductivity. When the open circuit potential decay of a nickel electrode is monitored in a molten carbonate environment three different regions are observed. The exact values observed depend on the thickness of the nickel electrode. A typical potential-time response is shown in Fig. 4.1. Three stages of oxidation/lithiation can be distinguished, which we believe are associated approximately with the reaction mechanisms shown in Table 4.2.

In the first region the electrode potential drops to a value corresponding the surface oxidation of the nickel electrode. The slope of this drop is strongly affected by the gas composition, thickness of, and depth of immersion of the electrode. After some time, a slower decrease of potential takes place, which suggests lithiation of the NiO lattice and formation of a highly conductive NiO electrode. In the second region, a potential arrest is observed, possibly suggesting an electrochemical process. This process may be the oxidation of $\mathrm{Ni}(\mathrm{II})$ to $\mathrm{Ni}(\mathrm{III})$ at the $\mathrm{NiO} /$ melt interface. When the potential reaches the second region it keeps a plateau value for a long time depending on the gas and electrode conditions. In this plateau region, lithiation is mainly taking place. If the electrode is fully immersed into electrolyte, the decreasing of potential is fast and a final electrode potential is reached. The slope of the decreasing potential plot is going to be reduced when the thickness of electrode is increased. When electrode is partially immersed, the same behavior is observed at longer times. Following the oxidation of the nickel surface, the oxide layer formed undergoes lithiation. This process increases the conductivity of the NiO electrode and the potential reaches a plateau. At the end of oxidation/lithiation process the electrode reaches the equilibrium potential.

At the lithiation stage, the oxidation of $\mathrm{Ni}(\mathrm{II})$ to $\mathrm{Ni}(\mathrm{III})$ in the $\mathrm{NiO}$ lattice takes place next to the nickel vacancies. Diffusion of the nickel vacancies requires that the charges carried by the excess oxide ions are neutralized. This is accompanied by the formation of two Ni(III) ions. The electrical conductivity of the electrode is caused by the diffusion of positively charged holes. Oxidation of a nickel electrode in an undoped environment provides conductivity varying from $10^{4}$ to $10^{-1} \Omega^{-1} \mathrm{~cm}^{-1}$ at $1000 \mathrm{~K}$. Depending on the oxidation time the lattice constant changes as well as the concentration of vacancies. Doping of the electrode with lithium increases the conductivity typically from 0.034 to $47 \Omega^{-1} \mathrm{~cm}^{-1}$ at $973 \circ \mathrm{K}$. The reason for this difference is that, 
Table 4.2. Stages of the oxidation/lithiation process of nickel.

Stage I: Initial NiO Surface Formation: (Region II)

solid:

$$
\begin{aligned}
& \mathrm{Ni}+\mathrm{O}^{2-} \rightarrow \mathrm{NiO}+2 \mathrm{e}^{-} \\
& \text {or } \\
& \mathrm{Ni}+\mathrm{CO}_{3}^{2-} \rightarrow \mathrm{NiO}+\mathrm{CO}_{2}+2 \mathrm{e}^{-}
\end{aligned}
$$

liquid:

$$
\begin{aligned}
& \mathrm{O}_{2}^{-} \stackrel{+\mathrm{e}^{-}}{\longrightarrow} \mathrm{O}_{2}^{=} \stackrel{2 \mathrm{e}^{-}}{\longrightarrow} 2 \mathrm{O}^{=} \\
& \mathrm{O}^{=}+\mathrm{CO}_{2} \rightarrow \mathrm{CO}_{3}^{2-}
\end{aligned}
$$

Stage II: [Oxidation-Lithiation ] of Inside Layer: $\quad$ (Region III)

$$
\mathrm{O}^{2-}(\mathrm{liq})+2 \mathrm{Ni}^{2+}+\mathrm{Li}^{+} \rightarrow 2 \mathrm{Ni}^{3+}+\mathrm{Li}[]^{\prime}+\mathrm{O}^{2-} \text { (sol) }
$$

For superoxide and peroxide;

$$
\begin{aligned}
& \mathrm{O}_{2}^{-}(\mathrm{liq})+5 \mathrm{Ni}^{2+}+\mathrm{Li}^{+} \rightarrow 5 \mathrm{Ni}^{3+}+\mathrm{Li}[]^{\prime}+2 \mathrm{O}^{2-} \text { (sol) } \\
& \text { and } \\
& \mathrm{O}_{2}^{2-}(\mathrm{liq})+4 \mathrm{Ni}^{2+}+\mathrm{Li}^{+} \rightarrow 4 \mathrm{Ni}^{3+}+\mathrm{Li}[]^{\prime}+2 \mathrm{O}^{2-} \text { (sol) }
\end{aligned}
$$

Stage III: Equilibrium: (Region IV)

$$
\begin{aligned}
& \mathrm{O}_{2}^{-}+\mathrm{e}^{-} \rightleftarrows \mathrm{O}_{2}^{=} \\
& \mathrm{O}_{2}^{=}+2 \mathrm{e}^{-} \rightleftarrows 2 \mathrm{O}^{=} \\
& \mathrm{O}^{=}+\mathrm{CO}_{2} \rightleftarrows \mathrm{CO}_{3}^{2-}
\end{aligned}
$$




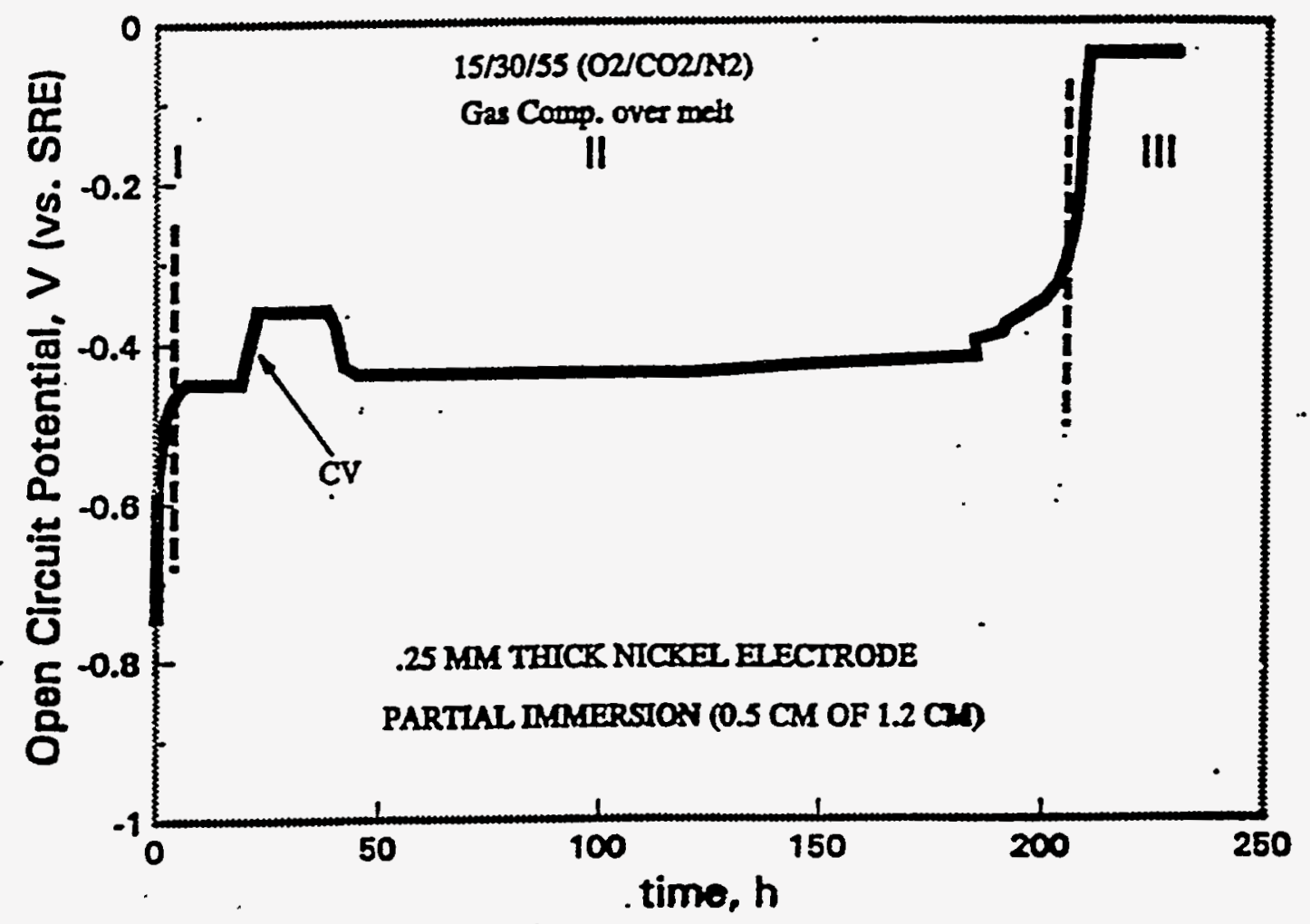

Fig.4-1 Characteristic potential-time curve for oxidation of partially submerged nickel foil in $\mathrm{Li}-\mathrm{K}$ carbonate. $\left(650^{\circ} \mathrm{C}, 1 \mathrm{~atm}, 0, \mathrm{CO}_{2} / \mathrm{N}_{2}: 15 / 30 / 55\right)$ 
in the case of the oxidation of nickel in presence of oxygen gas, the two Ni(III) are used to neutralize the negative charges. In the case of $\mathrm{Li}$ doping, lithium provides positive charges to neutralize excess oxide ions [Fig 4.2]. Therefore, the number of Ni(III) ions will be increased. One of the positive charge carried by the $\mathrm{Ni}^{3+}$ can be considered equivalent to a positive hole. The number of positively charged holes is linearly proportional to the conductivity. If we look at the lithiation process the possible reactions for the formation of vacancies are given in the following Table 4.3:

Table 4.3: Possible reactions for the oxidation and lithiation of a nickel electrode

for gas phase oxidation:

$$
\mathrm{O}_{2} \text { (bulk) }+6 \mathrm{Ni}^{2+} \rightarrow[]^{\prime \prime}+6 \mathrm{Ni}^{+++}+2 \mathrm{O}^{2-}
$$

for a lithium containing melt:

$$
\begin{gathered}
\mathrm{O}_{2}^{-} \text {(bulk) }+5 \mathrm{Ni}^{2+} \rightarrow[]^{\prime \prime}+5 \mathrm{Ni}^{3+}+2 \mathrm{O}^{2-} \\
\left(\mathrm{O}_{2}^{-} \text {(bulk) }+\mathrm{Li}^{+}+5 \mathrm{Ni}^{2+} \rightarrow \mathrm{Li}[]^{1}+5 \mathrm{Ni}^{3+}+2 \mathrm{O}^{2-}\right) \\
\mathrm{O}_{2}^{2-}(\text { bulk })+4 \mathrm{Ni}^{2+} \rightarrow[]^{\prime \prime}+4 \mathrm{Ni}^{3+} \\
\left(\mathrm{O}_{2}^{2-} \text { (bulk) }+\mathrm{Li}^{+}+4 \mathrm{Ni}^{2+} \rightarrow \mathrm{Li}[]^{\prime}+4 \mathrm{Ni}^{3+}+2 \mathrm{O}^{2-}\right) \\
\left.\mathrm{O}^{2-} \text { (bulk) }+2 \mathrm{Ni}^{2+} \rightarrow[]^{11}+2 \mathrm{Ni}^{3+}+\mathrm{O}^{2-}\right) \\
\left(\mathrm{O}^{2-} \text { (bulk) }+\mathrm{Li}^{+}+2 \mathrm{Ni}^{2+} \rightarrow \mathrm{Li}[]^{\prime}+2 \mathrm{Ni}^{3+}+\mathrm{O}^{2-}\right)
\end{gathered}
$$

[]": vacancy Li[ ]': vacancy site occupied by lithium ion.

The fast drop of potential at the end of the lithiation process can be explained as the end of formation of $\mathrm{Ni}(\mathrm{III})$ and quick consumption of previously formed trivalent ions. The open 


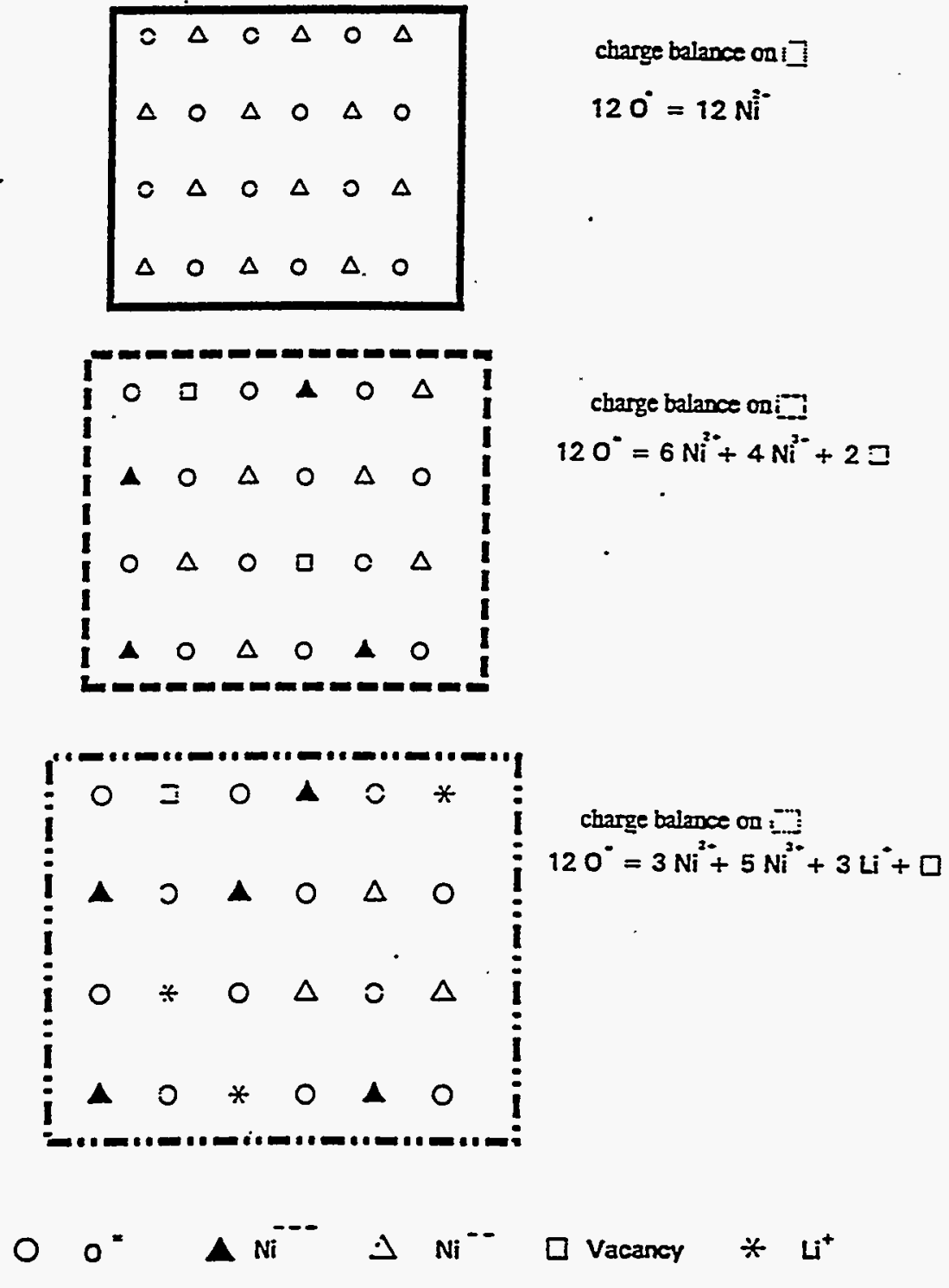

Fig.4.2. Schematic of solid-state oxidation-lithiation process: Cases are there is no defect formation, defect formation and finally doping with lithium 
circuit potential decay suggests that lithiation is not a chemical but an electrochemical (mixed potential) process. The cathodic peak that we observe in the $\mathrm{CV}$ of an in-situ oxidized/lithiated $\mathrm{NiO}$ electrode around $0.350-0.450 \mathrm{~V}$ is also evidence for a electrochemical process. Understanding these phenomena may be an important factor in understanding the dissolution of the MCFC cathode. When the lithiation process is over, the oxidation of $\mathrm{Ni}(\mathrm{II})$ to $\mathrm{Ni}(\mathrm{III})$ also stops. This may be a result of excess lithium concentration in the electrode. This excess lithium may use $\mathrm{Ni}(\mathrm{II})$ to form a Li-Ni-O component. During the lithiation $\mathrm{Ni}(\mathrm{III})$ is quickly consumed to form $\mathrm{Ni}(\mathrm{II})$. In the case of superoxide being present in the electrode,

$$
\mathrm{Ni}^{3+}+\mathrm{O}^{2-}+\mathrm{e}^{-} \rightarrow \mathrm{Ni}^{2+}+\mathrm{O}^{2-}
$$

or

$$
3 \mathrm{Ni}^{3+}+2 \mathrm{O}^{2-} \rightarrow 3 \mathrm{Ni}^{2+}+\mathrm{O}_{2}^{-}
$$

or

$$
2 \mathrm{Ni}^{3+}+2 \mathrm{O}^{2-} \rightarrow 2 \mathrm{Ni}^{2+}+\mathrm{O}^{2-}
$$

4.3.1. Conclusion: In summary, the stages of nickel oxidation/lithiation can be analyzed, with reference to [Fig. 4.1], as taking place in three stages having different characteristics.

Stage I: Initial NiO Surface Formation: Reaction in this region is very rapid (a few hrs.), then drops off to low rates.

Stage II: Oxidation-Lithiation of Interior Layer: The oxidation process continues, and lithium incorporation into the lattice starts to take place. The oxide layer formed in the previous stage causes limitations on diffusion of oxide species and lithium ions.

Stage III: Equilibrium: Stage I provides an oxide film at the surface. This film initially limits diffusion of reactants. In stage II, there is a gradient of oxide and lithium ions between the electrode surface and interior part of the electrode which is not initially oxidized or lithiated. Lithium incorporation into lattice seems slower than oxide diffusion. The presence of lithium in the lattice increases the diffusion coefficient of nickel ion in the $\mathrm{NiO}$ lattice because of the increased concentration of vacancies. When the previously formed oxide layer becomes porous, access of reactants to the reaction site is easier. 


\subsubsection{Visual Observations}

During the nickel oxidation experiment it is visually observed that most of the corrosion products are dissolved into the melt during the early stages of the oxidation/lithiation process.(Possibly, NiO particles lose contact with the inner nickel substrate and pieces drop into the electrolyte). These solid corrosion products are mostly collected at the surface of the ceramic tubes immersed into melt.

It is observed that the oxidized electrode has different layers. NiO formed on nickel consists of a black outer layer and a green inner layer which represents different oxidation levels. After oxidation, the electrode could easily be separated into two pieces, starting from the middle where there were a lot of white spots. Another interesting observation was the presence of a few black particles. These could be $\mathrm{NiO}$ deposits but there is also a possibility that they are carbon formed during CV application, at high negative potentials. The particles form a homogeneously distributed thin film at the surface of the crucible. Even when the nickel electrode was exactly in the middle of the crucible, a black colored film was formed at part of the crucible surface in contact with or covered by carbonate.

\subsection{3 $\mathrm{CV}$ under $\mathrm{CO}_{2}$ Gas Environment}

Cyclic voltammograms recorded while the sample was undergoing oxidation/lithiation and they confirm the potential at which lithiation takes place. The likelihood of certain electrochemical reactions can also be calculated from thermodynamic information (free energies of reactants and products). Cyclic Voltammetry was applied before the oxidation process and during lithiation. These measurement were used to distinguish between different electrode reactions. When the lithiation process is completed, the OCP of the NiO electrode reaches the oxygen equilibrium potential. In Fig. $4.3 \mathrm{CV}$ for a partially immersed Ni electrode under a pure $\mathrm{CO}_{2}$ oxidant gas environment(with a trace amount of oxygen) is shown.

Although no oxygen was present in the system, some oxygen leakage may have caused the rest potential to be around $-650 \mathrm{mV}$ during time in which cyclic voltammetry was applied in 


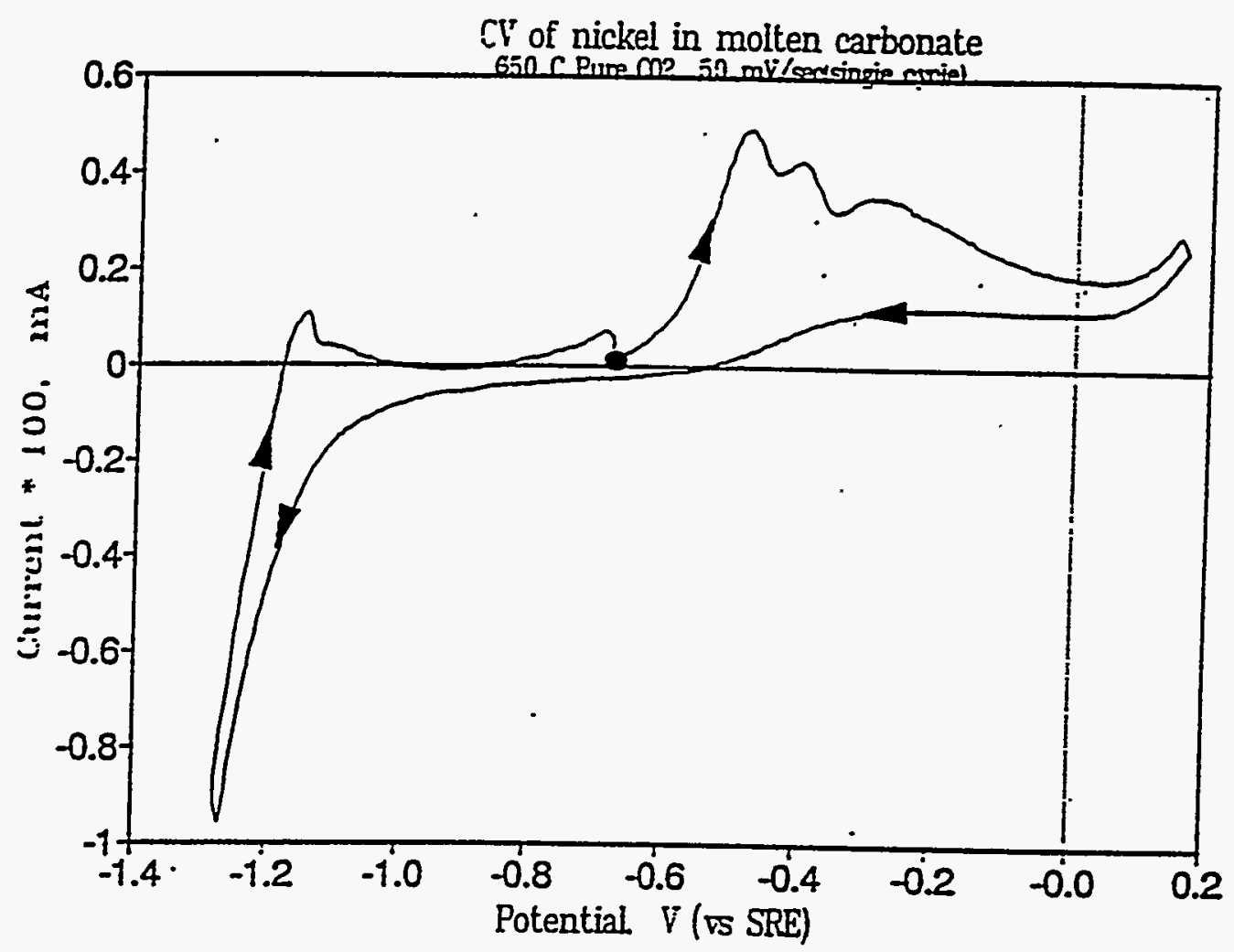

Fig.4.3. Cyclic Voltammogram of Nickel Electrode in Molten Carbonate 
the anodic direction. At positive potentials the sharp increase in current is attributed to the anodic oxidation of carbonate. A peak observed around $-0.4 \mathrm{~V}$ is assigned to lithiation of NiO electrode. The formation of trivalent nickel increases the conductivity of NiO electrode. This also increases the current corresponding to this reaction. In the reverse sweep, the current suddenly drops to potentials more negative than $-0.35 \mathrm{~V}$ because of the reduced conductivity. However, additional work is necessary to confirm this interpretation of potential-current behavior.

\subsection{Nickel Particle Behavior and Shorting}

Our initial approach to the problems to be addressed in steps 3 and 4 is as follows. Since lithiated $\mathrm{NiO}$ dissolves into the electrolyte at a rate of approximately $3 \%$ per thousand hours, efforts are necessary to develop a more stable $\mathrm{NiO}$ cathode structure. NiO dissolution from the cathode occurs continuously during the life of a cell but may not necessarily affect its performance. The performance of the cell is affected only when precipitated particles form a continuous precipitation zone (or line), consisting of metallic nickel or another type of conductor, which electrically connects cathode to anode. Time at which shorting starts depends not only on $\mathrm{CO}_{2}$ partial pressure and the temperature, but also on the matrix structure, i.e., on the porosity, pore diameter and, in particular, the thickness of the matrix. The MCFC is designed for operation at higher presșures, therefore the problem of $\mathrm{NiO}$ cathode dissolution and cell shorting has to be solved, in particular by considering the shorting phenomenon.

There are various reasons to assume that the nickel particles precipitated by reduction of dissolved nickel are unstable, and that some of them grow at the expense of others (Ostwald ripening). Additionally, the impurities and matrix defects can serve as nucleation sites for the nickel deposits. These deposits are mostly irregular in shape, however they can also occur in cubic crystal structure. This causes a porous kind of deposit. The overall growth of nickel particles must correspond to the flux of nickel into the tile, but the latter must also drive the spreading of the precipitation zone by forming additional deposition regions (secondary

precipitation zones). This phenomenon is similar to that of periodic precipitation (Liesegang rings). 
To develop a correlation that accurately predicts the shorting effect, the main parameters to be considered are the partial pressure of $\mathrm{CO}_{2}$, the temperature, the operation time, the thicknesses of cathode and the tile, the quantity of nickel particles distributed in the tile, the current density and the spatial distribution of the particles. The effect of additives on the long term performance and on the nucleation of nickel particles is not known.

The short circuit condition can be seen as the result of particular, localized particle distributions in the tile structure (Fig. 4.4). Such localized distributions can occur in different ways. One way is the formation of a deposit bridge along a crack in the $\mathrm{LiAlO}_{2}$ matrix structure. The matrix support material has to be stable for long term operation in order to prevent this type of short circuit. After thousands of hours of operation, the $\gamma-\mathrm{LiAlO}_{2}$ particle surface area decreases. This "coarsening" is the result of a dissolution-reprecipitation mechanism in the carbonate electrolyte.

Another short circuit path may result from the long term process involving nucleation and re-deposition as well as movement to the anode. The initial deposition point is strongly affected by the gas composition, however, when time advances particles may move to the anode as a result of the above processes while changing their size and size distribution. If one calculates the amount of nickel cathode dissolved over a cell life-time, it becomes clear that this is sufficient to cause a particle link if the particle size is small enough. The deposited particles must connect with each other from cathode to anode in order to cause a short circuit. This connection is made possible if there is a favorable local arrangement of nickel particles. Cracks in the matrix may accelerate it by forming nucleation sites for nickel particles.

When there is no crack in the matrix complete link of particles from cathode to anode must be formed. It is not easy to explain under which conditions this can happen, especially near the cathode. In the MCFC system deposition of metallic nickel as a cause of shorting may be considered due to an interconnection of spherical particles. This connection is not a continuous phenomenon, but it may be a combination of different effects over a period of time. When the cell is continuously operating the deposition and transportation of nickel particles takes place from the cathode side through the center of the matrix, and then at longer operation time spreading through the matrix toward the anode. The SEM picture (from IGT) suggests that 


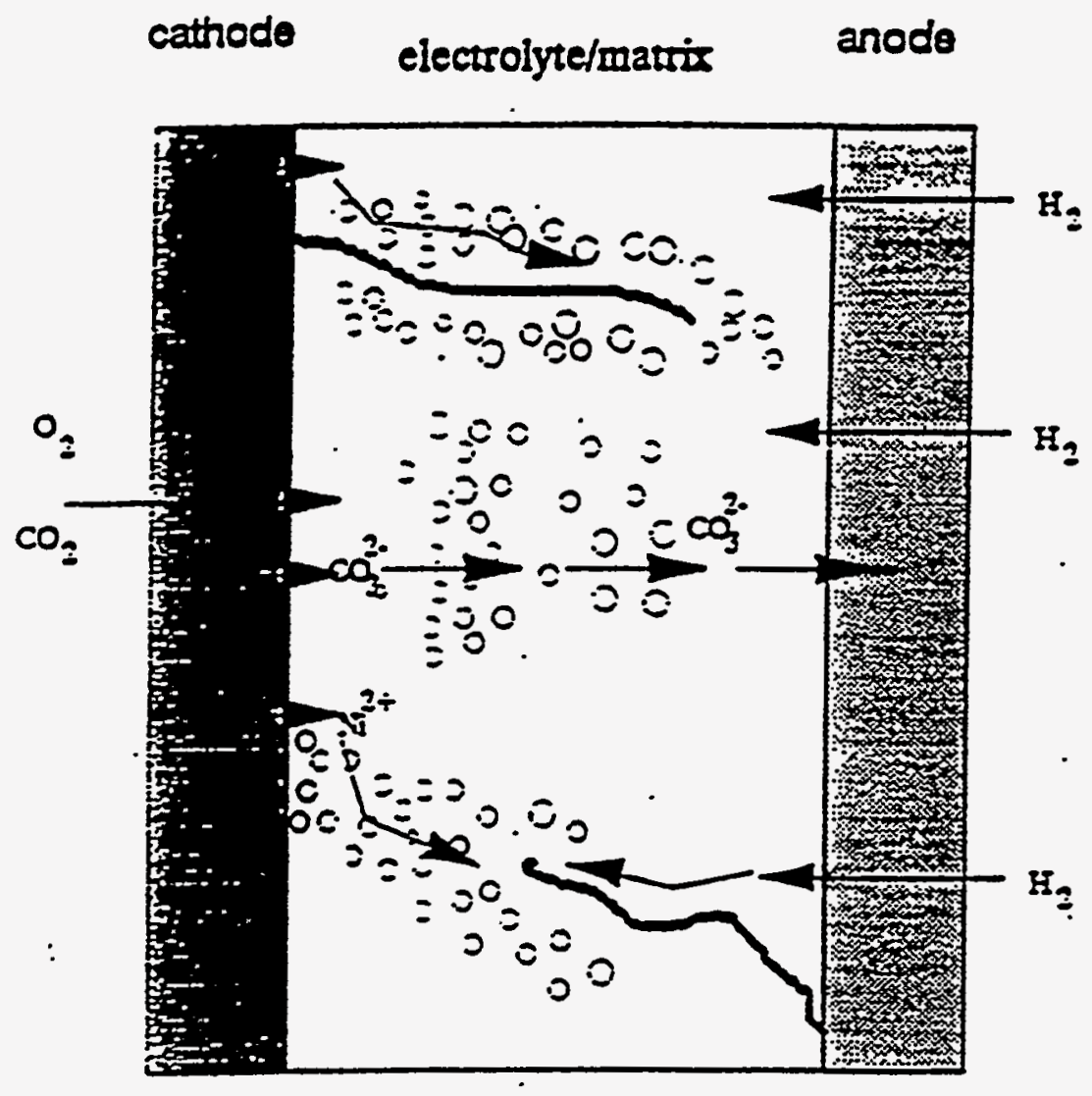

Fig 4-4. Schematic of sources leading to the short circuit in MCFC 
during the advancing and spreading of particles, the size of the particle deposits also changes. As long as dissolution and transport processes continue, local rearrangement of particles takes place.

It is not easy to evaluate quantitatively what are the factors affecting for this rearrangement. It is known from SEM analysis that the sizes of particles are restricted to certain levels. The particles may initially be considered as spherical particles. The surface tension of these particles keeps them at a certain size and location. The effect of diffusion. of gases on the size of a particle is important while the location of a particle is strongly affected by convection. The deposition process in the electrolyte is also coupled with the formation of water. High oxygen and low hydrogen concentration cause nickel ions deposit a certain distance from the cathode. Therefore we must always have a deposit free region at the cathode-electrolyte interface. Convection is one of the factors that explain the movement of the reaction front through the matrix.

Therefore, there is a possibility of connection of particles so as to form a conducting network that causes shorting between the electrodes. The connection is due to contact between spherical particles. The diameter of the contact point is small relative to the size of a particle, therefore the resistivity is high at that particular point. SEM analysis does not show any straight-line connections, but a relatively random network especially near the anode. This may be caused by the local structural changes of the matrix and may be related to gas distribution.

Time dependent processes often take the form of periodic precipitation phenomena, due to nucleation-diffusion interactions. - They vary in response to a number of controlling parameters. When current flows, segregation of additives and electrolytes may occur and lower the solubility of $\mathrm{NiO}$ in the matrix leading to deposition of nickel ions as NiO. Regional $\mathrm{CO}_{2}$ partial pressure and temperature distributions affect the deposition zone in the electrolyte. This may happen by a nucleation process in which local consumption of carbonate or convection brings new nickel particles closer to each other.

\subsection{Strategies to Prevent NiO Dissolution}

To study in particular the shorting mechanism, we plan the following: 
(1) to make use of pre-synthesized samples of nickel oxide, both as partially oxidized foil and as sintered NiO particles;

(2) to isolate and identify the effect of the lithiation process by repeating some of the experiments while varying the melt composition between standard $\mathrm{Li}^{+}$content and absence of $\mathrm{Li}^{+}$.

(3) to investigate the effect of temperature.

In further work we plan to investigate step 3. A better understanding of the forces driving convection and alignment of metal particles in the melt is absolutely necessary for a meaningful model of step 4 (formation of conduction paths). Conduction paths lowering the apparent resistance of a cell can be formed by physical contact of electronically conducting particles, but also by bipolar action of particle strings that are not physically continuous.

\subsection{Metal Solubility in Molten Carbonate}

The objective of this sectionis to analyze dissolution behavior of electrode and hardware metals in $15 / 30 \%\left(\mathrm{O}_{2} / \mathrm{CO}_{2}\right)$ gas environment. Solubility of metals in $62 / 38 \%\left(\mathrm{Li}_{2} \mathrm{CO}_{3} / \mathrm{K}_{2} \mathrm{CO}_{3}\right)$ mixture is analyzed by combining electrochemical and sampling methods. In each experiment, the current-potential behavior of a particular metal electrode is investigated also under a reducing gas environment.

For the electroanalytical analysis of metal ion solubility, an inert electrode (usually gold) is used as the working electrode. There are two ways to generate solutions in the melt. In the first, an excess amount of the oxide whose solubility is to be determined is placed in the melt. In that case alumina or ceramic tubes are used to collect small amounts of melt in successive time periods. These are analyzed by AA or ICP methods to determine the concentration of dissolved metal. The disadvantage of this sampling method is that the sample may contain some undissolved metal oxide particles. In the second method, a certain amount of metal ion is added to the melt coulometrically. Both cases provide calibration line for peak current vs. concentration.

When the potential is scanned through cathodic and anodic limits, the magnitude of the peak currents is related to scan rate and concentration of metal ions in the melt. For a reversible 
reaction, the peak current and concentration of electrochemical active species (in this case dissolved metal ion) are related by;

$$
I_{p}=0.4463 A C_{0} \cdot \sqrt{\frac{n^{3} F^{3}}{R T}} \sqrt{D} \sqrt{w}
$$

where $A$ the electrode area, $C^{*}$ and $D$ the bulk concentration and diffusivity of the electroactive component, $v$ scan rate. The slope of the $\mathrm{dI}_{\mathrm{p}} / \mathrm{d}\left(v^{1 / 2}\right)$ plot will yiels the concentration of metal ions in the melt if the diffusivity is known. Alternatively, from a known concentration (sampling method) of metal the diffusivity can be estimated(Figure 4.5 ).

Based on the above theoretical consideration, species in the melt are deposited at the surface of an inert (In this case, gold) electrode by holding the potential at cathodic values for a certain period of time. Then, scanning anodically will remove(strip) the species from the surface of the inert electrode. This method is called 'Anodic Stripping Voltammetry'. Current peak locations are used to identify species in the melt and peak heights give information about how much of the particular species is present in the melt. The magnitude of the peak current, which is related to the holding time, is increased as dissolution continues over time. This method requires pre-knowledge of metal ion concentration in the melt( Figure 4.6).

Another method of electroanalytical concentration measurement is 'Square Wave Voltammetry'. This technique allows one to perform quantitative analyses very fast. It has the advantage of reduced background current and subtracts the capacitive current. The output is a wave form which provides peak current location for the ions in the solution(Figure 4.7). Concentrations lower than $10^{-8} \mathrm{~mol} / \mathrm{l}$ can be detected by SWV. Another advantage is the reproducibility of the data with various shapes of electrode. SWV provides the same peak potential and shape regardless of electrode geometry. At a planar electrode, the peak current can be expressed as:

$I_{p}=0.9653 \mathrm{AnFC}_{0}^{*} \sqrt{f D} \tanh \left(\beta_{S H V} / 2\right)$ 


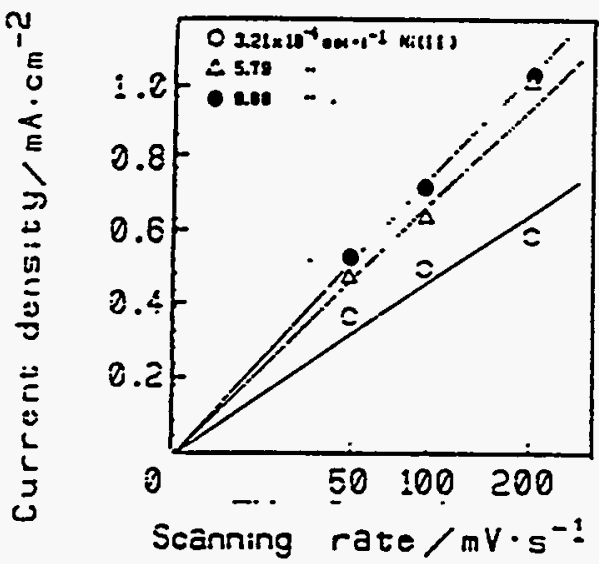

(Abserssa : squaro root scalo)

Fig. 4.5. Peak current scan rate relation for carbonate melt containing $\mathrm{Ni}^{2+}$ ions.(Ref. 15) 


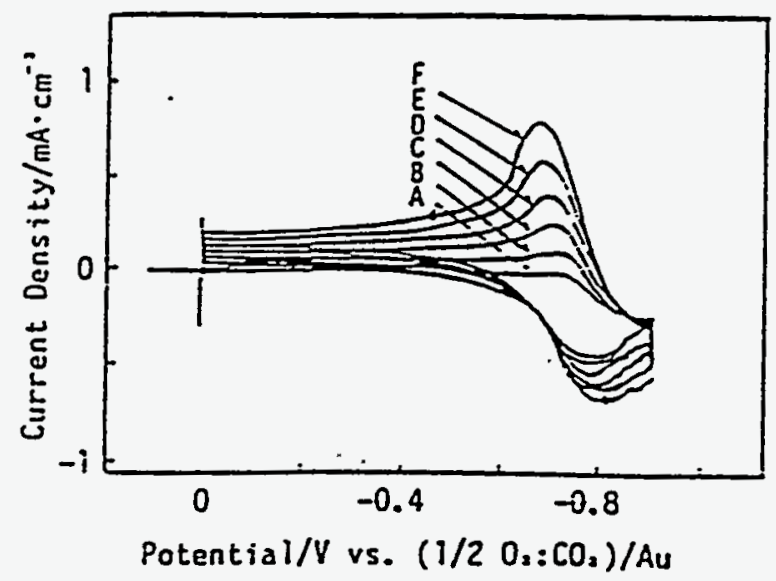

Fig. 4.6. $\mathrm{i}-\mathrm{V}$ characteristics on $\mathrm{Au}$ in molten carbonate melt containing $\mathrm{Ni}^{2+}$ ions. For cathodic scan, the potential is held at $-0.9 \mathrm{~V}$ for A: $0, \mathrm{~B}: 1, \mathrm{C}: 2, \mathrm{D}: 3, \mathrm{E}: 4, \mathrm{~F}: 5$ minutes, then, potential is anodically scanned (Ref. 16). 


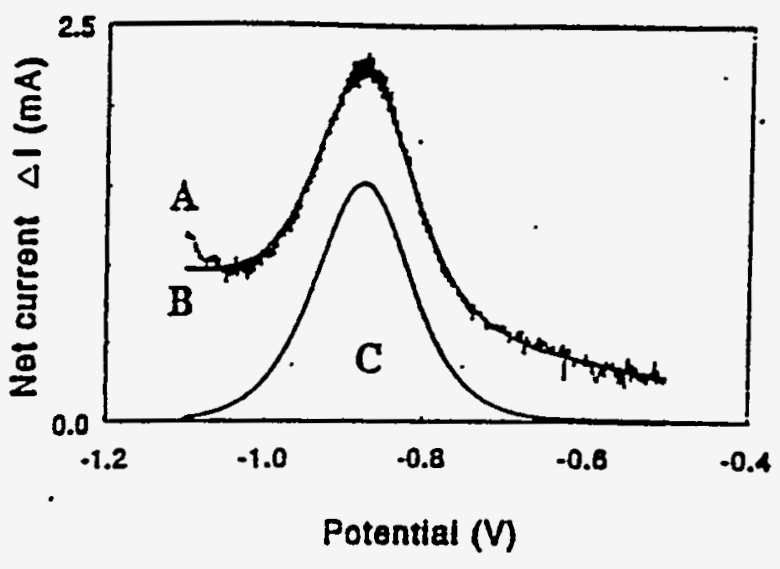

Fig. 4.7. Square Wave Voltammogram of carbonate melt containing $\mathrm{Co}^{2+}$ ions at $923 \mathrm{~K}$. The experimental curve A is fitted with the curve B. $C$ is the background-current-free voltammogram for the peak current(Ref. 17). 
where $f$ is the square wave frequency, $\beta$ is the dimensionless square wave amplitude defined as $\mathrm{nFE}_{\mathrm{SW}} / \mathrm{RT}$, with $\mathrm{E}_{\mathrm{SW}}$ square wave amplitude. Using known diffusion coefficient of metal ions in the carbonate melt, their concentration can be determined.

The integral of a bell- shaped voltammogram gives the total area for a large planar electrode:

$\mathrm{S}_{\mathrm{T}}=1931 \mathrm{AnFC} C_{0}^{*} E_{S T \sqrt{f D}}$

The ratio of the above two equations will give the expression for the number of electrons involved in the process

$\mathrm{n}=\frac{\mathrm{RT}}{\mathrm{FE}_{\mathrm{SW}}} \ln \left(\frac{1+2 \mathrm{E}_{\mathrm{SW}} I_{\mathrm{P}} / S_{T}}{1-2 \mathrm{E}_{\mathrm{SW}} I_{P} / S_{T}}\right)$

From the total area, which is the product of current and potential, the charge consumed may be determined:

$Q=4 \underset{\pi}{2}-1 / 2 \operatorname{CAnFC} C_{0}^{*} \sqrt{D / f} \beta_{S W W}$

where $\mathrm{C}$ ranges from 0.371 to 0.381 .

The above expressions can be used to obtain the maximum amount of information about electrochemically active species.

Experiments to determine nickel concentration are continuing. Some available diffusivity information is going to be used in mathematical analyses. Because of software problems with electrochemical equipment, some of the data could not be analyzed to date. Following this experiment using nickel, $\mathrm{Fe}$ and stainless steels 310 and 316 will be used to collect solubility information for the components of these metals and alloys in a carbonate environment, under various gases. 


\section{REERENCES}

[1]. M. Matsumura and J.R. Selman, J.Electrochemical Soc., 139 (1992) 1255-1261

[2]. G.L. Lee, "Dynamic Analysis of MCFC Porous Electrode", Ph.D. Thesis (1992)

[3]. C.Y.Yuh and J.R.Selman, J.Electrochemical Soc., 131 (1984) 2062-2069

[4]. H.R.Kunz, L.J.Bregoli and S.T.Syzmanski, J. Electrochem. Soc., 131(1984)2815-2821

[5]. E. Fontes, C. Lagergren and D. Simonsson, Electrochim. Acta 38 (1993) 2669-2682

[6]. J.A. Prins-Jansen, C.J. van Duyn, K. Hemmes and J.H.W. de Wit,"Mathematical Analysis of the Agglomerate Model for Porous Electrodes", in Proc. Third Intern. Symposium Carbonate Fuel Cell Technology, PV93-3, The Electrochemical Society Inc., Pennington NJ 08534 (1993) p.468-485

[7]. C.Y. Yuh, "Potential Relaxation and AC Impedance of Porous Electrodes", Ph.D. dissertation, Illinois Institue of Technology, 1985

[8]. C.Y. Yuh and J.R. Selman, J.Electrochemical Soc. 138 (1991) 3642-3648

[9]. Y.H. Kim and J.R. Selman, "Mechnism of Low- $\mathrm{CO}_{2}$ Performance of the MCFC Cathode", in

"Molten Salts" Proc. 9th Int. Symp.; PV 94-13, The Electrochemical Society Inc., Pennington, NJ, pp.781-787

[10]. Yong-Hwan Kim, "Mechanism of Low- $\mathrm{CO}_{2}$ Performance of the MCFC Cathode", M.S. Thesis, Illinois Institute of Technology, August 1994.

[11]. D.A. Shores, J.R. Selman and E.T. Ong, "Cathode Dissolution", Final Report to U.S. Department of Energy, Contract DE-AC21-86MC23263 (1989)

[12]. K. Ota, S. Mitsushima, S. Kato, S. Asano, H. Yoshitake, and K. Kamiya, J.Electrochem.Soc. 139 (1992) 667

[13]. J.B.J. Veldhuis, S.B. van der Molen, R.C. Makkus and G.H.J. Broers, Ber: Bunsenges. Phys.Chem. 94 (1990) 947

[14] P.G.P. Ang and A.F. Sammells, J. Electrochem. Soc., 127, p1287 (1980).

[15].Ito,Y.,Tsuru, K., Oishi, J.,Miyazaki, Y.,Kodama, T., "Dissolution Behavior of Copper and Nikel Oxide in Molten $\mathrm{Li}_{2} \mathrm{CO}_{3} / \mathrm{K}_{2} \mathrm{CO}_{3}{ }^{\prime \prime}$, J. Power Sources,23(1988)357-364

[16].Ogura, H., Ito,Y,Murata, K.,Shirogami, T, "Dissolution of Cathode Nickel in Molten Carbonates I. In-situ Measurement of Dissolved $\mathrm{Ni}^{2+}$ Concentration by means of Anodic Stripping Method", Denki Kagaku, 55, (1987),392-395

[17]. Veldhuis, J.B.J,Eckes, F.C.,Plomp,L., "The Dissolution Properties of $\mathrm{LiCoO}_{2}$ in Molten 62:38 mol\% Li:K Carbonate", J. Electrochem.Soc., 139, L6-L8,1992 